\title{
The potential role of the antioxidant and detoxification properties of glutathione in autism spectrum disorders: a systematic review and meta-analysis
}

\author{
Penelope AE Main ${ }^{1,2^{*}}$, Manya T Angley ${ }^{1}$, Catherine E O'Doherty ${ }^{1}$, Philip Thomas ${ }^{2}$ and Michael Fenech²
}

\begin{abstract}
Background: Glutathione has a wide range of functions; it is an endogenous anti-oxidant and plays a key role in the maintenance of intracellular redox balance and detoxification of xenobiotics. Several studies have indicated that children with autism spectrum disorders may have altered glutathione metabolism which could play a key role in the condition.

Methods: A systematic literature review and meta-analysis was conducted of studies examining metabolites, interventions and/or genes of the glutathione metabolism pathways i.e. the $\gamma$-glutamyl cycle and trans-sulphuration pathway in autism spectrum disorders.

Results: Thirty nine studies were included in the review comprising an in vitro study, thirty two metabolite and/or co-factor studies, six intervention studies and six studies with genetic data as well as eight studies examining enzyme activity.

Conclusions: The review found evidence for the involvement of the $\gamma$-glutamyl cycle and trans-sulphuration pathway in autistic disorder is sufficiently consistent, particularly with respect to the glutathione redox ratio, to warrant further investigation to determine the significance in relation to clinical outcomes. Large, well designed intervention studies that link metabolites, cofactors and genes of the $\gamma$-glutamyl cycle and trans-sulphuration pathway with objective behavioural outcomes in children with autism spectrum disorders are required. Future risk factor analysis should include consideration of multiple nutritional status and metabolite biomarkers of pathways linked with the $\gamma$-glutamyl cycle and the interaction of genotype in relation to these factors.
\end{abstract}

Keywords: $\gamma$-glutamyl cycle, Trans-sulphuration pathway, Metabolites, Genes, Supplementation, Autism spectrum disorders

\section{Background}

Autism spectrum disorders are a heterogeneous group of neurodevelopmental conditions comprising autistic disorder which is characterised by impairments in reciprocal social interaction and communication and the presence of stereotyped behaviours, Asperger's Syndrome which is distinguished by no significant delay in early language acquisition or cognitive abilities, and

\footnotetext{
* Correspondence: penelope.main@csiro.au

'Sansom Institute for Health Research, University of South Australia, City East Campus, Adelaide, SA 5000, Australia

Full list of author information is available at the end of the article
}

pervasive developmental disorder - not otherwise stated (PDD-NOS) in which individuals do not fully meet the criteria for autistic disorder or Asperger's syndrome. Over the last 30 years the number of diagnosed cases has increased from $0.4-0.5$ to 4.0 per 1000 for autistic disorder and from 2 to 7.7-9.9 per 1000 for autism spectrum disorders [1-3] which is largely attributable to broadening diagnostic criteria, younger age at diagnosis and improved case ascertainment [4]. Autism spectrum disorders are increasingly being recognised as a major public health issue.

\section{() Biomed Central}


While the exact cause of autism is unknown, a strong genetic component has been identified as shown by family and twin studies which have found concordance rates of $82-92 \%$ in monozygotic twins compared with $1-10 \%$ in dizygotic twins, sibling recurrence risk at $6-8 \%$ and heritability estimates of $>90 \%[5,6]$. Recent studies have shown that autistic disorder is likely to involve multiple genes [7-9] although a common genetic change is not seen in all cases suggesting that it is likely to be a cluster of conditions, each with its own individual and yet overlapping pathology. Environmental factors such as heavy metal toxicity [10-12], sub-clinical viral infections [13] and gastro-intestinal pathology [14,15], as well as endogenous toxins produced by metabolic processes [16], hormones (reviewed in [17]) and gastro-intestinal bacteria $[18,19]$ have also been suggested as playing a role in the aetiology of the disorder, although none of these have been thoroughly investigated. Large, well designed studies, such as the Childhood Autism Risks from Genetics and Environment (CHARGE) [20], are currently underway to further elucidate the role of genes and environment.

Cellular detoxification systems are of critical importance in providing protection against the effects of endogenous and exogenous toxins. Glutathione redox and the glutathione-s-transferases reviewed below constitute one such system.

\section{Glutathione redox and autism spectrum disorders}

Glutathione (L- $\gamma$-glutamyl-L-cysteinyl-glycine) is an intracellular peptide that has a wide range of functions including detoxification of xenobiotics and/or their metabolites $[21,22]$, maintenance of the intracellular redox balance [23], and is the major endogenous antioxidant produced to combat free radical insults [24-26]. Other metabolic functions include cysteine storage [21], signal transduction [27] and apoptosis [28].

Within the cell, approximately $90 \%$ of glutathione is located in the cytosol, $10 \%$ in the mitochondria and a small percentage in the endoplasmic reticulum [29]. Approximately $85 \%$ of total cellular glutathione is free and unbound whilst the rest is bound to proteins [30]. Glutathione is synthesised in the cytosol in two steps (Figure 1).

The first step of glutathione synthesis involves the formation of glutamylcysteine from glutamate and cysteine in an ATP dependent reaction catalysed by glutamatecysteine-ligase (GCL) which requires either $\mathrm{Mg}^{2+}$ or $\mathrm{Mn}$ ${ }^{2+}$ as a cofactor. This is considered to be the rate limiting step because it is dependent on the bioavailability of cysteine and the activity of GCL, the latter of which is modified by competitive inhibition by reduced glutathione (GSH) [31-34]. In the second step, glutathione synthetase (GS) adds glycine to glutamyl-cysteine to form glutathione ( $\gamma$-glutamyl-cysteinyl-glycine).

More than $98 \%$ of total glutathione is present as GSH and the rest is found as the oxidised form, glutathione disulfide (GSSG) or a range of glutathione-S-conjugates. GSH is readily converted to GSSG by the seleno-enzyme glutathione peroxidase (GPx) during periods of oxidative stress, and is reverted to the reduced form by glutathione reductase (GSH-R) [35]. GSH is also important in detoxification as it is used to conjugate a wide variety of exogenous compounds including carcinogens, toxins and drugs and endogenous electrophiles. The glutathione conjugate is subsequently secreted from the cell [36].

Glutathione degradation takes place in the extracellular space. Cysteine is released from extracellular glutathione by $\gamma$-glutamyl-transferase (GGT) located on the apical surface of the kidney, intestine and the epithelia of most transporting ducts, including the liver and bile ducts [37]. Expression of GGT is tissue and developmental stage specific and its activity may be induced by certain xenobiotics [37]. GGT hydrolyses the $\gamma$-glutamyl bond of glutathione or glutathione-S-conjugates and transfers the $\gamma$-glutamyl moiety to an acceptor molecule, often an amino acid [38]. If the substrate is glutathione, cysteinylglycine is released and subsequently cleaved into cysteine and glycine by cell surface dipeptidases. The $\gamma$-glutamyl amino acid can be transported back into the cell where $\gamma$-glutamyl cyclo-transferase (GCT) releases the acceptor amino acid to form 5-oxo-proline, the latter of which is converted back to glutamate by oxo-prolinase and used for GSH synthesis.

About half the cysteine used for glutathione synthesis is produced by the trans-sulphuration pathway [33]. The trans-sulphuration pathway involves conversion of homocysteine to cystathione and ultimately to cysteine in two vitamin B6 dependent reactions catalysed by cystathione- $\beta$-synthase and cystathione lyase respectively (Figure 2). The remainder is obtained through the diet and protein catabolism. The trans-sulphuration pathway is closely linked to the folate-methionine cycle and is particularly active in the liver and absent or less active in other tissues, the foetus, neonates and in patients with homocysteinemia [39]. Neurones depend on glial cysteine for glutathione synthesis as they lack the trans-sulphuration pathway which in turn results in them being more susceptible to oxidative stress [40].

Glutathione status is an accurate indicator of cell functionality and viability [41-43]. The ratio of GSH: GSSG (glutathione redox ratio) is a sensitive index of oxidative stress, which can lead to a toxic imbalance between the production and removal of reactive oxygen species (ROS). A shift in the glutathione redox ratio towards the oxidised state may lead to decreased cell 


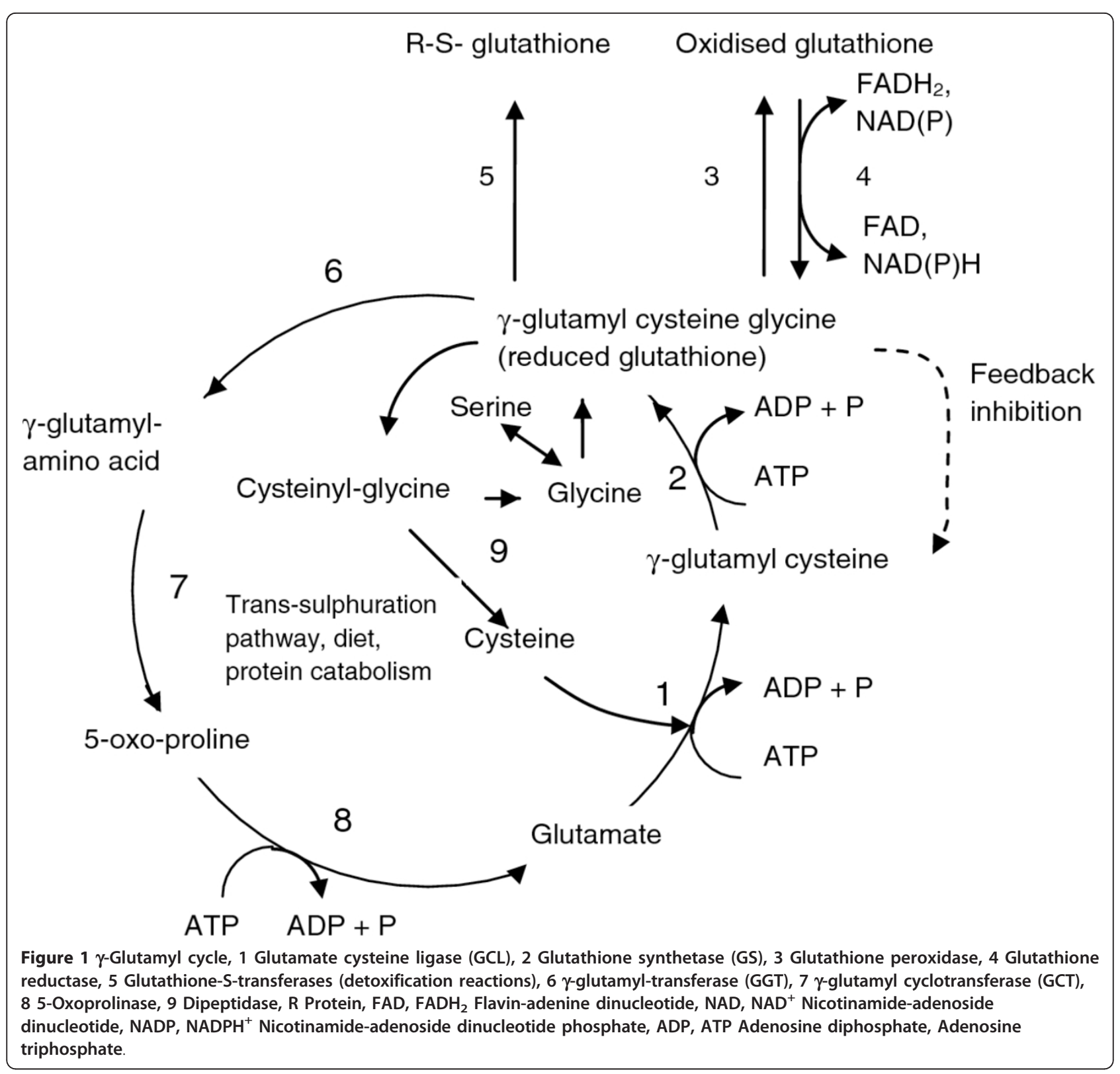

$$
\text { Serine } \overbrace{\text { Cystathione }}^{\text {Homocysteine }} \text { Vit. B6 }
$$

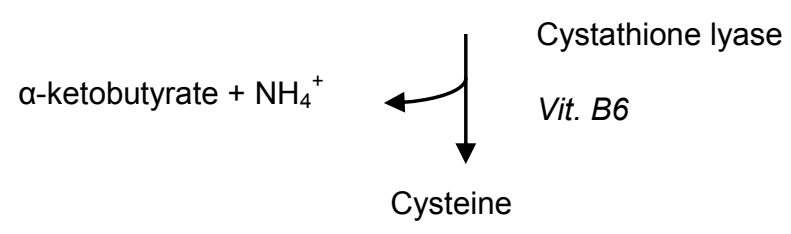

Figure 2 Trans-sulphuration pathway Vit. B6 Vitamin B6. 
proliferation, DNA damage [44] and increased apoptosis [45] that could potentially affect neurological development in the early stages of life. As a decreased glutathione redox ratio has also been reported in many studies of individuals with autistic disorder [46-50], it may be hypothesised that a shift in the glutathione redox ratio may play a role in the aetiology of autism. This article systematically reviews the evidence for a role of glutathione redox in the aetiology of autism spectrum disorders and considers the research questions:

1) Is there an association between metabolites/cofactors/genes/enzymes of the $\gamma$-glutamyl cycle or transsulphuration pathway and autism spectrum disorders?

2) If so, does normalisation of metabolite levels of the $\gamma$-glutamyl cycle or trans-sulphuration pathway lead to clinically significant improved outcomes for children with autism spectrum disorders?

\section{Methods}

\section{Selection of studies for review}

The inclusion criteria for studies were defined as:

(a) participants diagnosed with an autism spectrum disorder using standardised criteria such as the American Psychiatric Association's Diagnostic and Statistical Manual of Mental Disorders (DSM)-IV-R [51] or the Childhood Autism Rating Scale (CARS) scores [52]; and

(b) data for metabolites, co-factors, genes and/or enzymes associated with the $\gamma$-glutamyl cycle or the trans-sulphuration pathway, and/or

(c) interventions using metabolites or cofactors of the $\gamma$-glutamyl cycle or the trans-sulphuration pathway.

(d) full text English language articles published between 1970 and November 2011.

\section{Information retrieval}

Information retrieval was performed using the following electronic databases: Embase, Medline, Cinahl, Scopus, Web of Science and International Pharmaceutical Abstracts (search terms in the Supplementary On-line Material). In addition, studies were identified from the reference lists of obtained published articles, editorials and known studies. Authors were contacted if not enough data was included in the original manuscript for analysis, for clarification of terms or to confirm whether the article contained data previously published by the same research group.

All potential studies identified were independently evaluated for inclusion by two primary reviewers. The primary reviewers were not blinded to the authors, institutions or source of publication at any time during the selection process. Disagreements about the inclusion/exclusion of studies were discussed and consensus achieved. Provision was made for a third reviewer if consensus was unattainable but did not prove necessary. When multiple papers from a single study had been published, we used the latest publication and supplemented it with data from the earlier publication(s).

\section{Data extraction and methodological quality assessment}

Data extraction for each included study was performed by PM and checked by two primary reviewers (MA, CO'D). Differences were resolved by consensus. The Newcastle Ottawa Scale [53] for case control studies was modified to assess the methodological quality of observational articles for the review (Table 1). The quality of each article was independently assessed by two primary reviewers (PM and COD) and assigned a score. Using a similar process, the risk of bias for intervention trials included in the review omitting the case report [54] was assessed using the criteria set out in the Cochrane Collaboration Handbook [55]. In addition, a level of evidence was assigned to each study using the Australian National Health and Medical Research Council criteria (Table 2) [56].

\section{Statistical analyses}

The kappa coefficient was calculated to assess the level of agreement for the quality scores between the two coders [57]. Statistical heterogeneity was assessed for key metabolites of the $\gamma$-glutamyl cycle, trans-sulphuration pathway and GSH:GSSG using the Review Manager 5 (RevMan) statistical software [58]. Duplicated data presented in more than one publication by the same authors was not included in the statistical analysis. Meta-analysis was conducted using a random effects model where heterogeneity was low to moderate $\left(\mathrm{I}^{2}=0-60 \%\right)$. Where possible, the studies were stratified according to autism spectrum disorder. Standard deviation was calculated using StatSak statistical software prior to analysis using the RevMan program for studies that published the standard error of the mean rather than the standard deviation $[59,60]$. Studies are reported using the MOOSE (Meta-analyses of observational studies) Statement [61] and the STREGA (STrengthening the REesporting of Genetic Association studies) checklists [62].

\section{Results}

Sixty six abstracts were identified via the electronic and hand search strategy. Of these, 24 were ineligible for inclusion. Reasons for exclusion were: 1) the paper did not contain any relevant data; 2 ) the data was already published in another article identified in the search; 3) data did not include the proband with an autism spectrum disorder; 4) the paper was a review article, conference abstract or comment on a previously published article; 5) the authors did not separate data for autism spectrum disorders from other psychological conditions; or 6) they were not English 
Table 1 Modified Newcastle Ottawa Scale

\begin{tabular}{|c|c|c|}
\hline 1. Selection & & \\
\hline \multirow[t]{3}{*}{ Case definition } & Yes, with independent validation & 2 \\
\hline & Yes, record linkage/self report & 1 \\
\hline & No description & 0 \\
\hline \multirow[t]{2}{*}{ Representativeness } & Consecutive cases & 1 \\
\hline & Potential for selection bias/not stated & 0 \\
\hline \multirow{3}{*}{$\begin{array}{l}\text { Selection of } \\
\text { controls }\end{array}$} & Community & 2 \\
\hline & Hospital/clinic/school & 1 \\
\hline & Potential for selection bias/not stated & 0 \\
\hline \multirow[t]{4}{*}{$\begin{array}{l}\text { Definition of } \\
\text { controls }\end{array}$} & $\begin{array}{l}\text { No family history of autism spectrum } \\
\text { disorder }\end{array}$ & 2 \\
\hline & $\begin{array}{l}\text { Healthy/other psych/developmental/ } \\
\text { genetic }\end{array}$ & 1 \\
\hline & disorder & \\
\hline & Poorly defined/not stated & 0 \\
\hline
\end{tabular}

2. Comparability of cases and controls on the basis of the design

\begin{tabular}{|c|c|c|}
\hline Study controls for age & & 1 \\
\hline Study controls for gender & & 1 \\
\hline \multicolumn{3}{|l|}{ 3. Exposure } \\
\hline \multicolumn{3}{|l|}{ Ascertainment of exposure } \\
\hline & aboratory blinded to case/control status & 1 \\
\hline & aboratory unblinded/not stated & 0 \\
\hline \multicolumn{3}{|c|}{ Method of ascertainment same for cases and controls } \\
\hline Yes & es & 1 \\
\hline No & & 2 \\
\hline \multicolumn{3}{|c|}{ 4. Additional criteria for genetic studies } \\
\hline \multicolumn{3}{|c|}{ a. Consideration of Hardy Weinberg Equilibrium } \\
\hline Yes & es & 1 \\
\hline No & o & 0 \\
\hline \multicolumn{3}{|l|}{ b. Power calculations } \\
\hline Yes & es & 1 \\
\hline No & o & 0 \\
\hline \multicolumn{3}{|c|}{ c. Correction for multiple comparisons } \\
\hline Yes & es & 1 \\
\hline No & o & 0 \\
\hline \multicolumn{3}{|c|}{ d. Adjustment for population stratification } \\
\hline Yes & es & 1 \\
\hline No & o & 0 \\
\hline
\end{tabular}

language articles with the exception of a seminal French study widely referred to in English language papers [63] (Figure 3).

Forty two studies were included in the review (41 that met the inclusion criteria plus the French study). Of these, one provided data obtained from in vitro models of $\gamma$-glutamyl cycle metabolites, twenty nine provided data on metabolites and/or co-factors of the $\gamma$-glutamyl cycle or trans-sulphuration pathway, six provided the results of intervention studies, six included genetic data and eight studies provided data on enzyme activity.

An overview of the studies included in this review is presented in Table 3. The level of evidence, study size and ascertainment of cases and controls are indicated along with a quality assessment score and/or assessment of risk of bias. Most studies were of the case control design, however, additionally there were two double blinded $[64,65]$ and one open labelled randomised controlled trial [49], a case series [66] and a case report [54].

An assessment of study quality is presented in Tables 4, 5, 6 and 7. The case definition used to include participants in the studies varied over time. The case definition for autistic disorder was not standardised until 1980 when it was included in the DSM-III. Asperger's Syndrome and PDD-NOS were added to the DSM-IV in 1994 which broadened the definition to include many children who were previously undiagnosed. While early studies centred on cases obtained from institutionalised psychiatric settings $[92,93,98]$, cases were later recruited through internal research registers [64], multiple centres $[47,50,64,70,71,88,95,96]$ or community advertisements [75]. Although diagnosis was independently confirmed in several studies $[59,60,69,70,72,75,83,85,91,92]$, most relied on medical records or parent reports. None of the studies had used a structured sampling frame for case ascertainment making them prone to selection bias. Information about case ascertainment was not provided for eight studies [48,49,54,59,74,78,81,84].

Ascertainment and definition of controls also varied widely. While two studies sourced their controls by community advertising $[75,86]$, most were sourced from hospitals, clinics or schools $[71,72,77,79,83,85,88,92,93]$ and fourteen studies did not provide information on the source of their controls $[48,59,60,63,68-70,73,74,76,78,81,84]$. With respect to definition of controls, most studies recruited healthy children with no information about family history of autism spectrum disorders, although, four studies did ensure that controls did not have either a family history or sibling with autism $[70,75,77,87]$ and one screened for autism traits [59]. At the other end of the scale, controls for four studies were poorly defined potentially biasing the results $[46,47,89,98]$. Control values from one of these studies [47] were used for two later studies $[49,50]$. Additionally, three studies relied on laboratory reference ranges $[65,92,93]$.

Gender is a potential confounder in studies of autistic disorder because the condition is four times more common in males than females [99]. Only five studies were gender matched $[60,73,75,83,89]$, four did not provide the gender of cases or controls $[50,59,71,89]$ and nine provided the gender of cases but not controls [46-48,50,70, $73,79,83,91]$. Age may also be a potential confounder as 
Table 2 Australian National Health and Medical Research Council Designated Levels of Evidence ${ }^{1}$

\begin{tabular}{|c|c|}
\hline $\begin{array}{l}\text { Level of } \\
\text { evidence }\end{array}$ & Description \\
\hline $\mathrm{I}$ & Evidence obtained from a systematic review of all relevant randomised controlled trials. \\
\hline II & Evidence obtained from at least one properly designed randomised controlled trial. \\
\hline III - 1 & Evidence obtained from well designed pseudo-randomised controlled trials (alternate allocation or some other method). \\
\hline III - 2 & $\begin{array}{l}\text { Evidence obtained from comparative studies with concurrent controls and allocation not randomised (cohort studies), case } \\
\text { control studies or interrupted time series with control group. }\end{array}$ \\
\hline III - 3 & $\begin{array}{l}\text { Evidence obtained from comparative studies with historical control, two or more single arm studies, or interrupted time series } \\
\text { without a parallel control group. }\end{array}$ \\
\hline IV & Evidence obtained from a case series, either post-test or pre-test and post-test. \\
\hline
\end{tabular}

serum glutamate was elevated in adults with autistic disorder compared to adult controls [75] but was not significantly different in children with autistic disorder compared to child controls $[69,70]$. In contrast, serum glycine and serine were not significantly different in either adults [75] or children [69,70] when levels in autistic disorder were compared to controls. One study included a range of participants from childhood to early adulthood, however, the findings were not stratified according to age [88].

All studies included in the review treated cases and controls equally. Laboratory blinding as to case and control status occurred for only one research group $[65,76,87]$, although others were blinded to case status but not controls, for example, where the laboratory provided the control data $[88,90,91]$ or reference ranges $[65,67,92,93]$ or where another study was used for controls $[49,50]$. Most studies did not state whether the laboratory was blinded.

Genetic studies were assessed for quality using the Newcastle Ottawa Scale plus additional criteria that included consideration of Hardy Weinberg equilibrium, power of the study, population stratification and correction for multiple comparisons. All except one of the six genetic studies considered Hardy Weinberg equilibrium $[47,50,94,96,97]$, two provided power calculations $[96,97]$ and two adjusted for multiple comparisons [50,97] (although a footnote indicating that the associations were no longer statistically significant was not added in one case) [50]. While population stratification is not relevant for transmission linkage studies [94-97], neither of the remaining studies were adjusted for this $[47,50]$.

Both of the double blinded randomised intervention trials provided information about concealment and the laboratory was blinded thereby reducing performance and detection bias $[64,65]$. Neither provided information about the randomisation process, complete outcome data and full reporting of results. While Bertoglio et al. 2010 state that 30 children completed the 12-week trial, closer inspection of the paper suggests that at least 32 children started the trial (see Table 1 in Bertoglio et al. 2010), however, no information on dropout or loss to follow-up was provided. Furthermore outcome data was only provided for the 'responder' sub-group in a form that was difficult to interpret. Adams et al. 2009 randomised children to receive either topical glutathione or a placebo before being given one round of a chelating agent with erythrocyte glutathione tested at baseline and 1-2 months following the intervention [65]. It is not clear whether it is a typographical error, however, Table 1 of the study states that 77 children participated in the first phase of the study, but baseline data for erythrocyte glutathione is only provided for 72 children. Although the paper states that 49 started the second phase of the study and therefore, according to the protocol, had a second glutathione measurement, pre- and post-intervention erythrocyte glutathione is only provided for 38 participants with no comparison between the two arms of the study with levels being compared to an adult reference range provided by the laboratory. The second phase of the study involved 'high excreters' of urinary metal ions being given a further 6 rounds of chelation if allocated to the topical glutathione arm or 6 rounds of placebo if previously allocated to the topical placebo arm of the study. Erythrocyte glutathione was not measured at the completion of the second phase of the study.

The open-label study design used in the remaining three intervention studies left them at high risk of selection, performance and detection bias $[46,49,65]$, however, all studies provided complete outcome data and full reporting of results.

A kappa score of 0.87 was obtained which indicates a high level of agreement between raters for the assessment of quality of articles.

\section{In vitro studies of the $\gamma$-glutamyl cycle}

Table 8 summarises the findings of an in vitro study of $\gamma$-glutamyl cycle metabolites [80]. Decreased free glutathione (fGSH) and increased GSSG were observed in both cytosol and mitochondrial extracts obtained from 


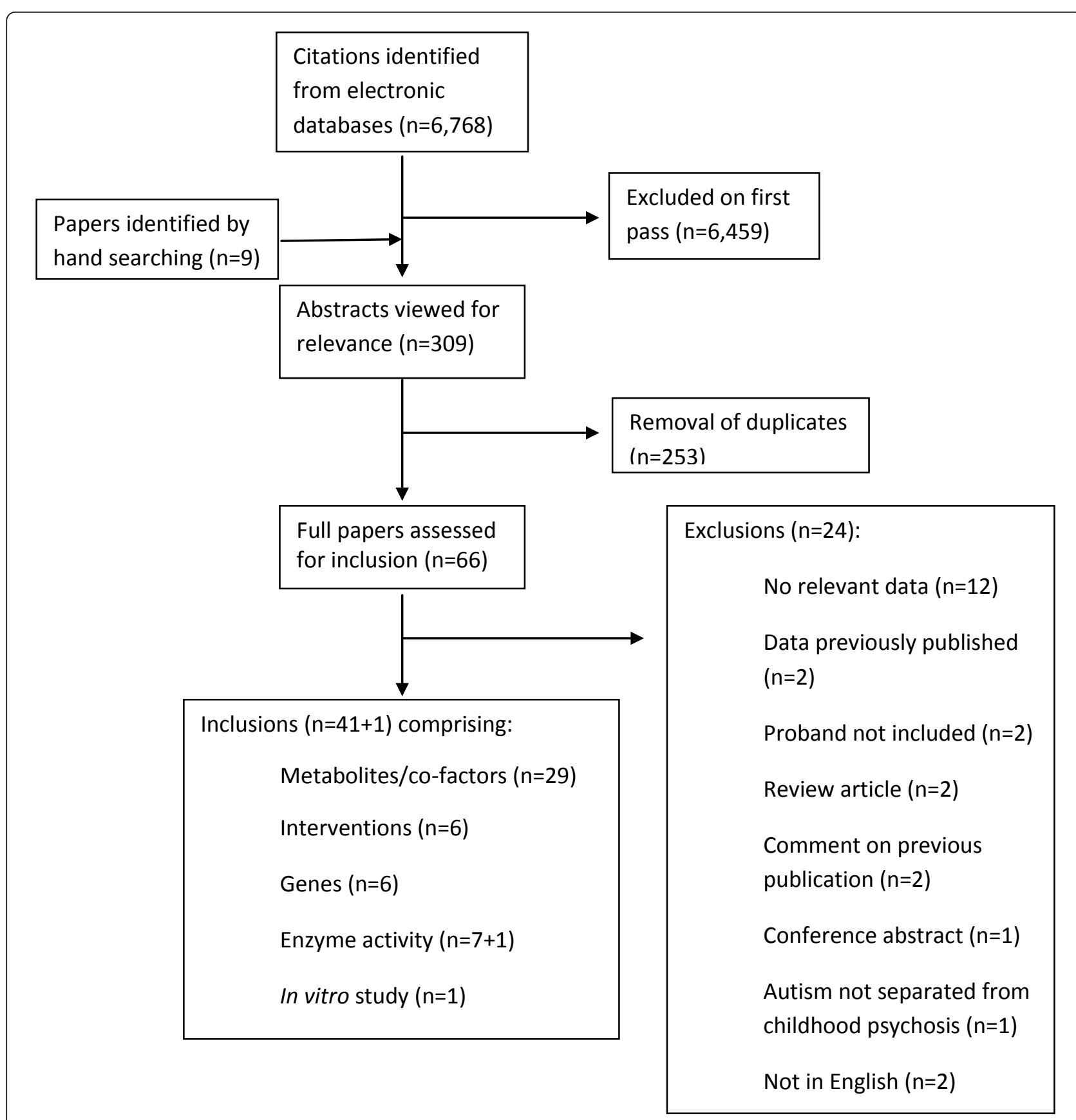

Figure 3 Flow diagram of research papers retrieved for potential inclusion in our study.

lymphoblastoid cell lines derived from children with autistic disorder compared to unaffected controls resulting in a decreased GSH:GSSG. Exposure to physiological levels of nitrosative stress showed no difference in the magnitude of GSH:GSSG from cells derived from children with autistic disorder compared to healthy controls, however, the baseline GSH:GSSG was significantly lower (by 30\%) in cells from children with autistic disorder.
Metabolites and cofactors of the $\gamma$-glutamyl cycle and trans-sulphuration pathway

Data from key studies of metabolites of the $\gamma$-glutamyl cycle and trans-sulphuration pathway is shown in Figures 4, 5 and 6 and a summary of additional studies presented in Table 9.

The largest and most comprehensive study to date provided data for multiple metabolites of the $\gamma$-glutamyl cycle and trans-sulphuration pathway [47]. This study 


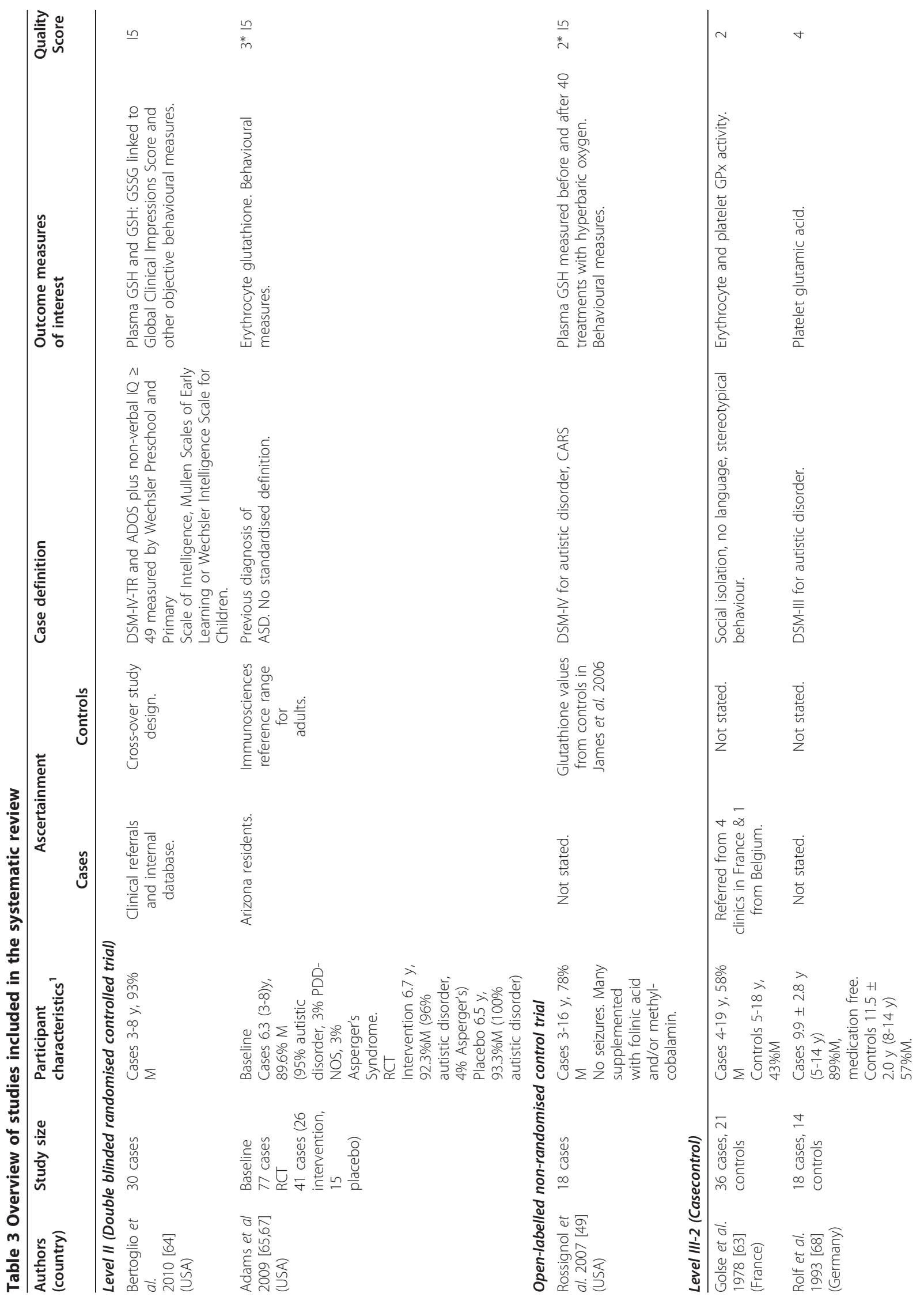




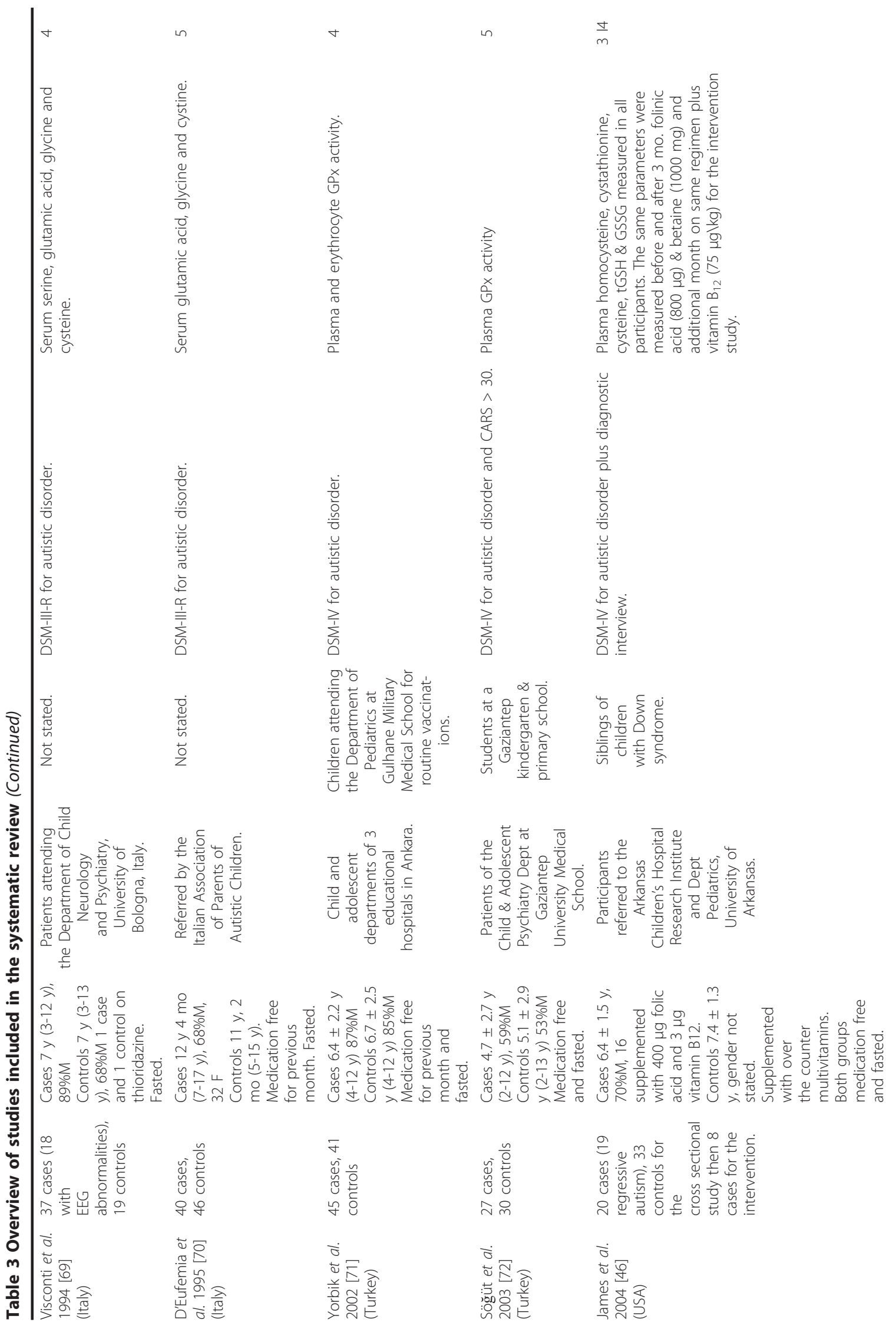




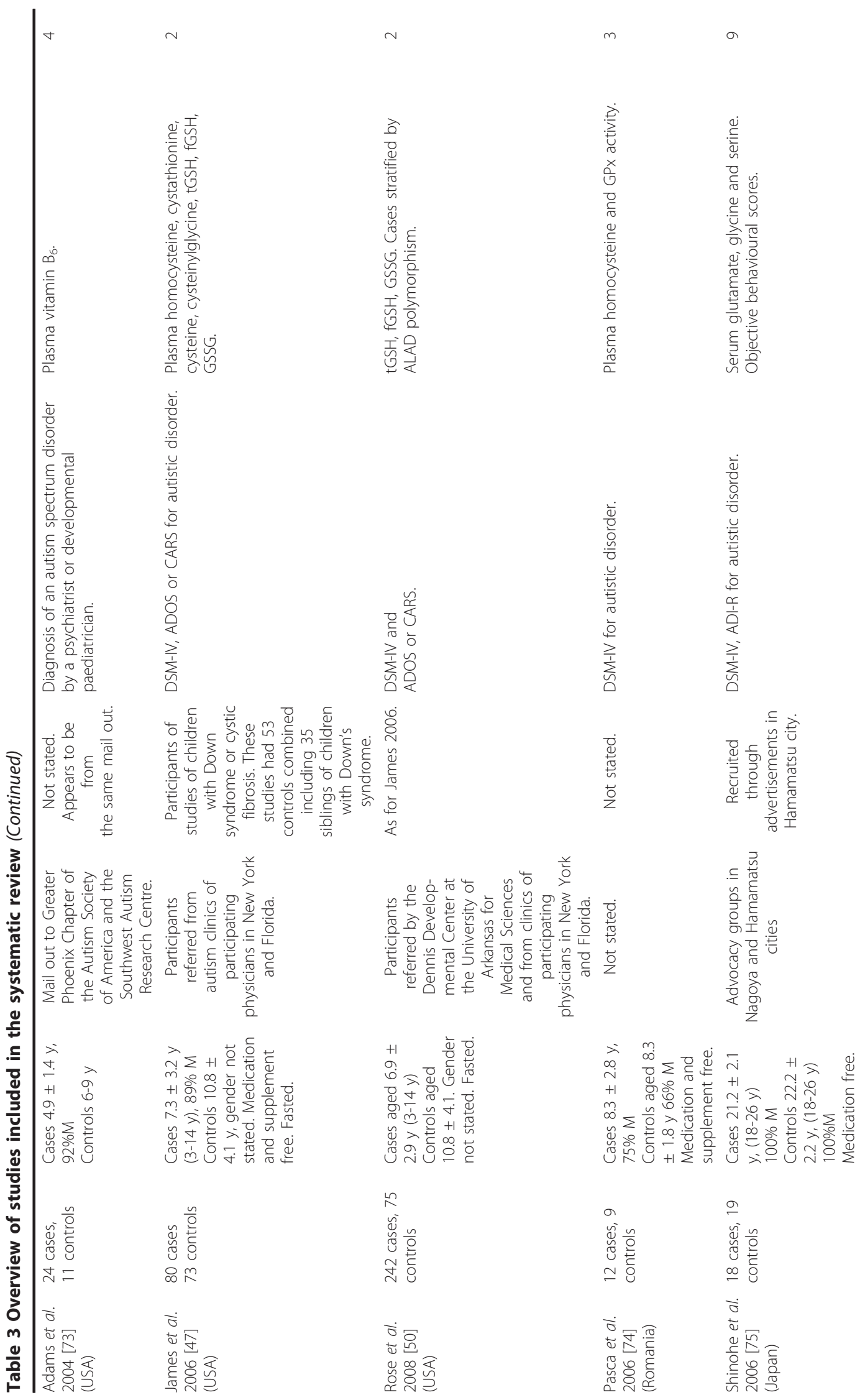




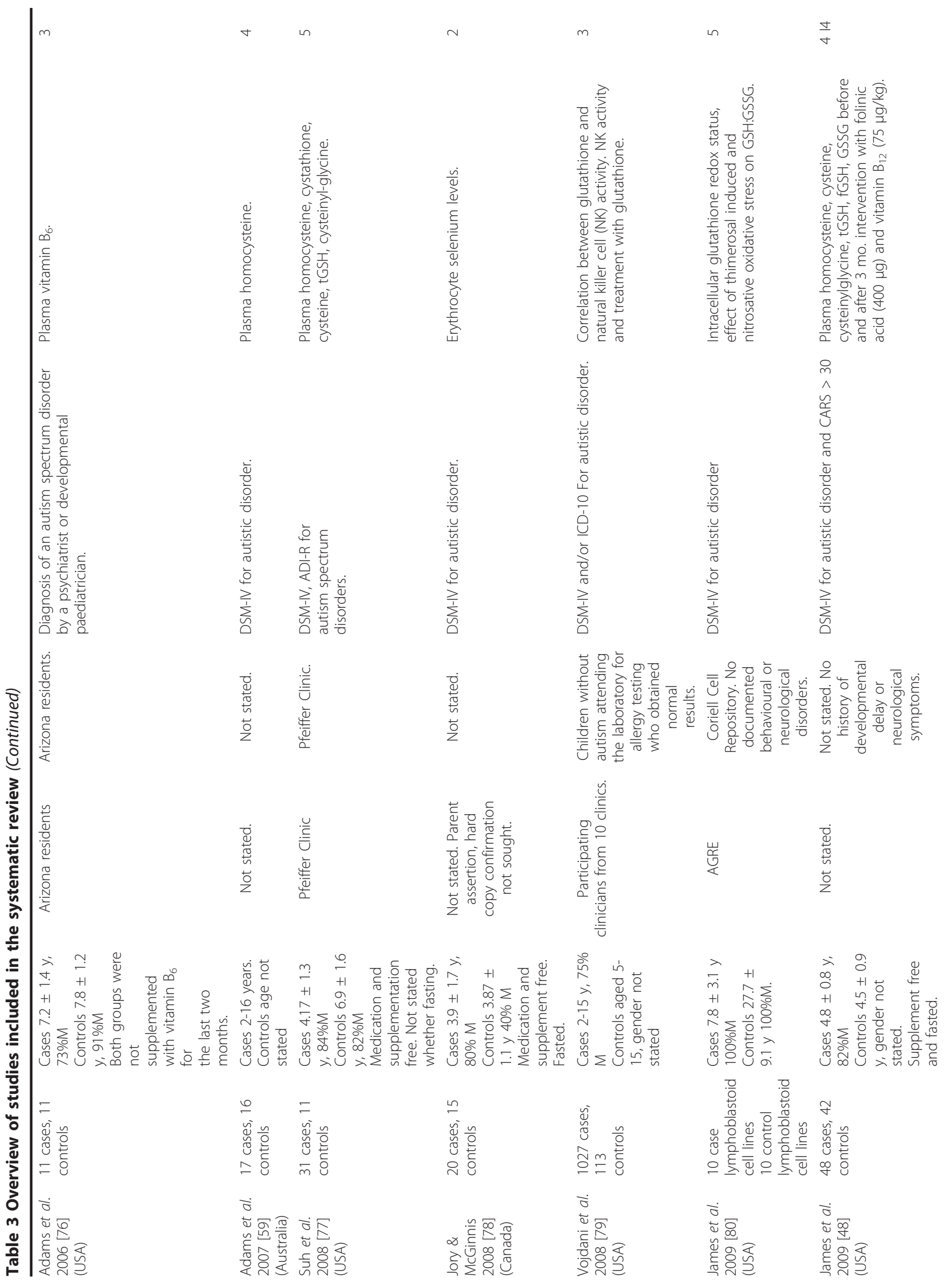




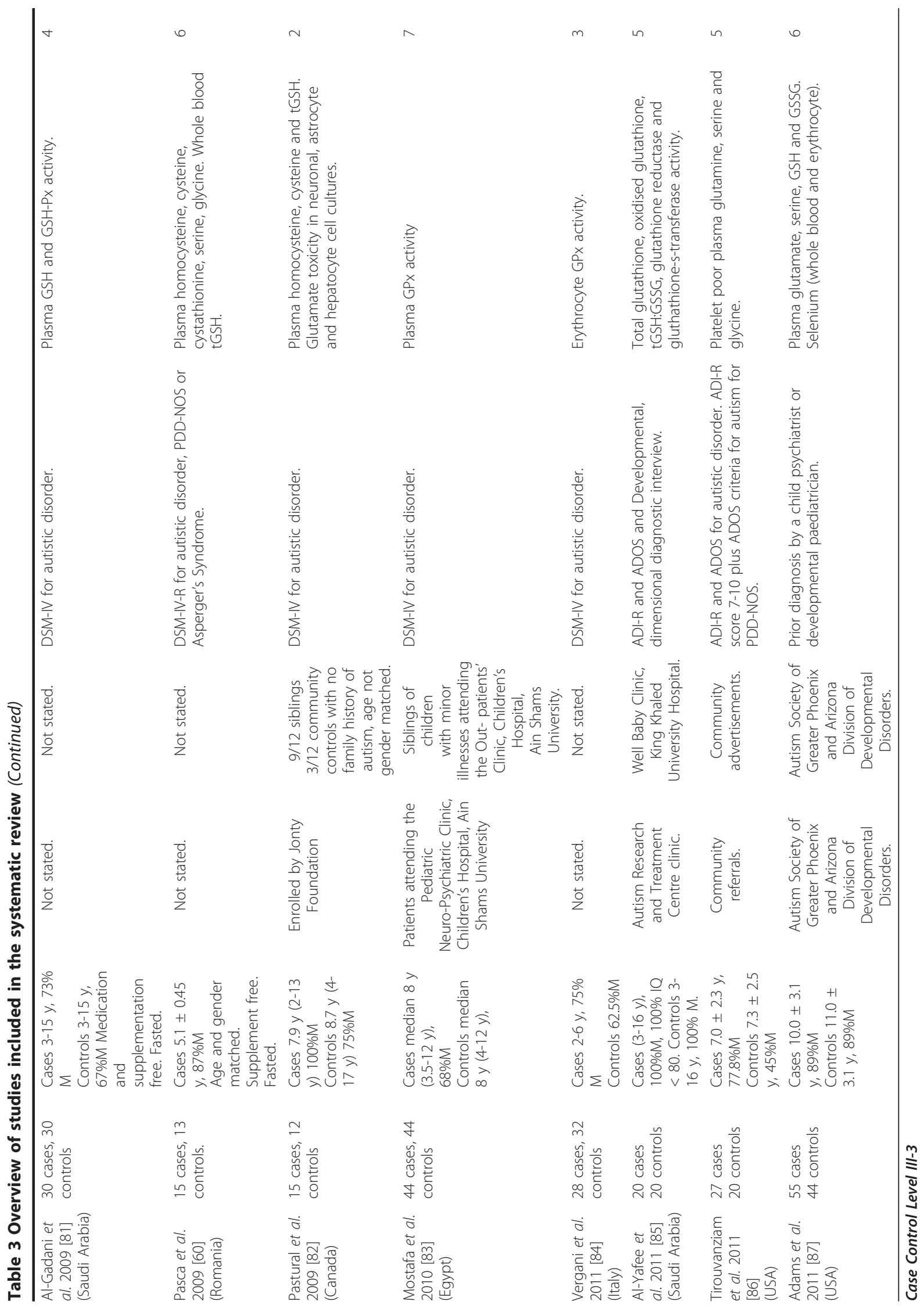




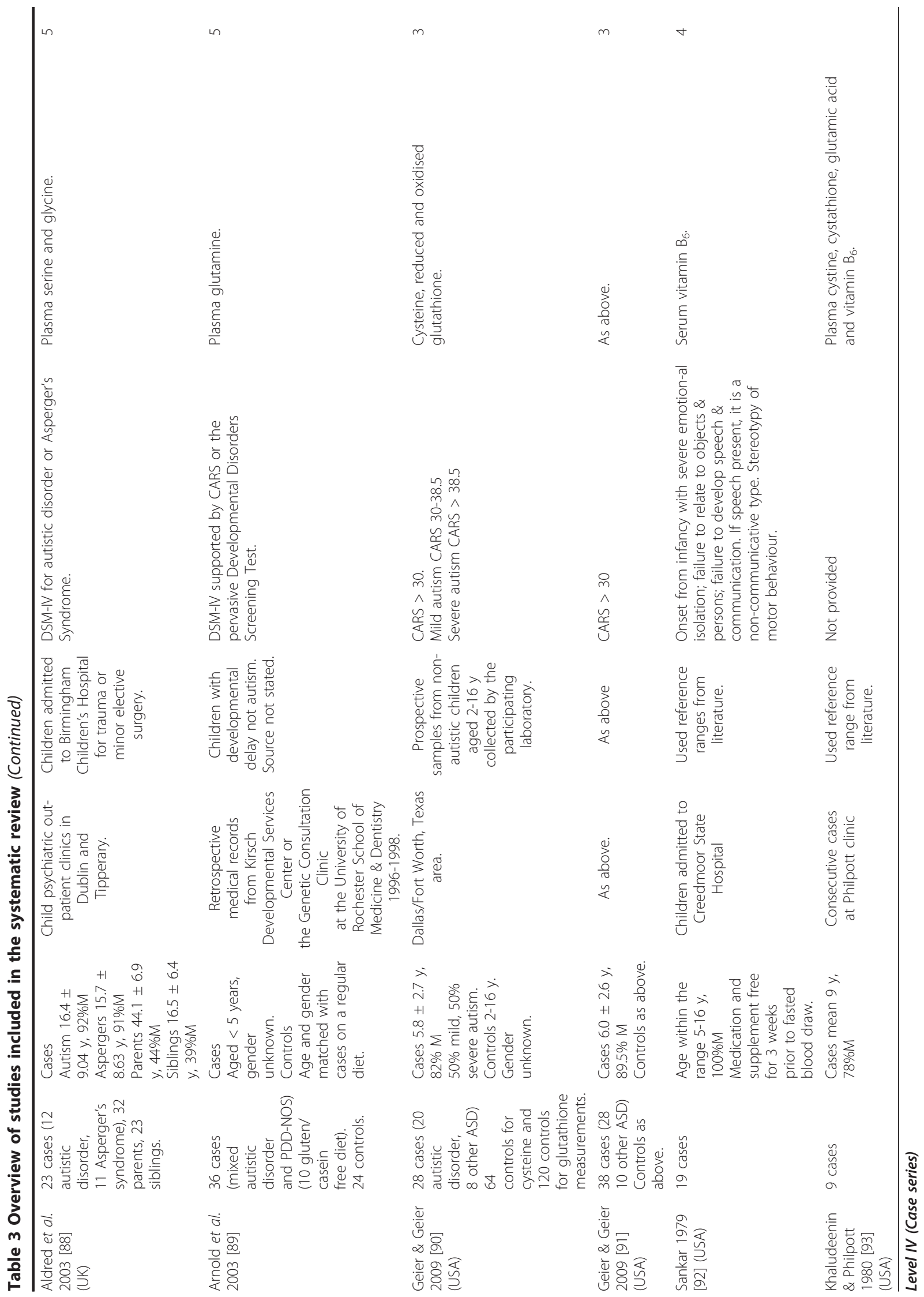




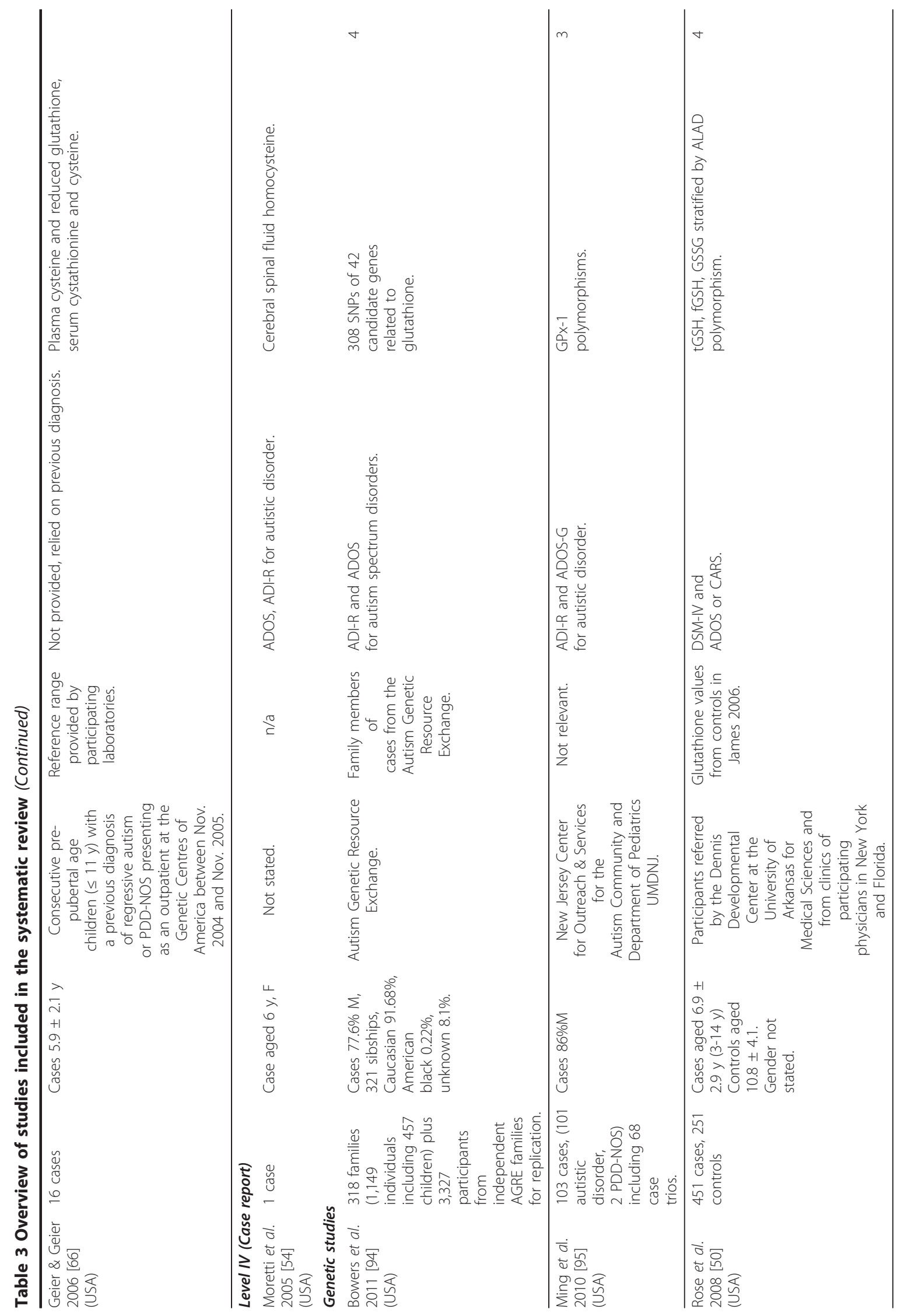




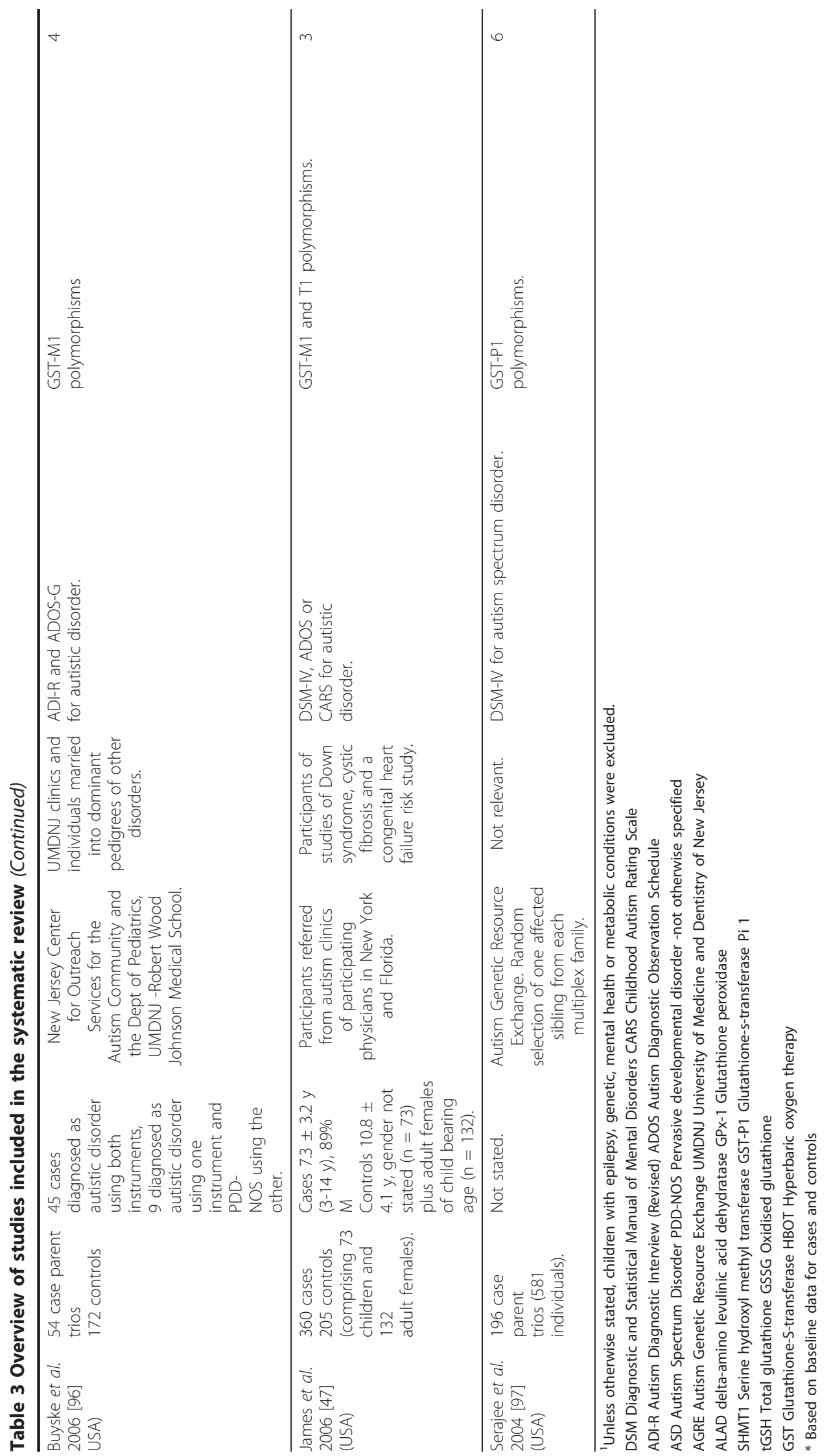




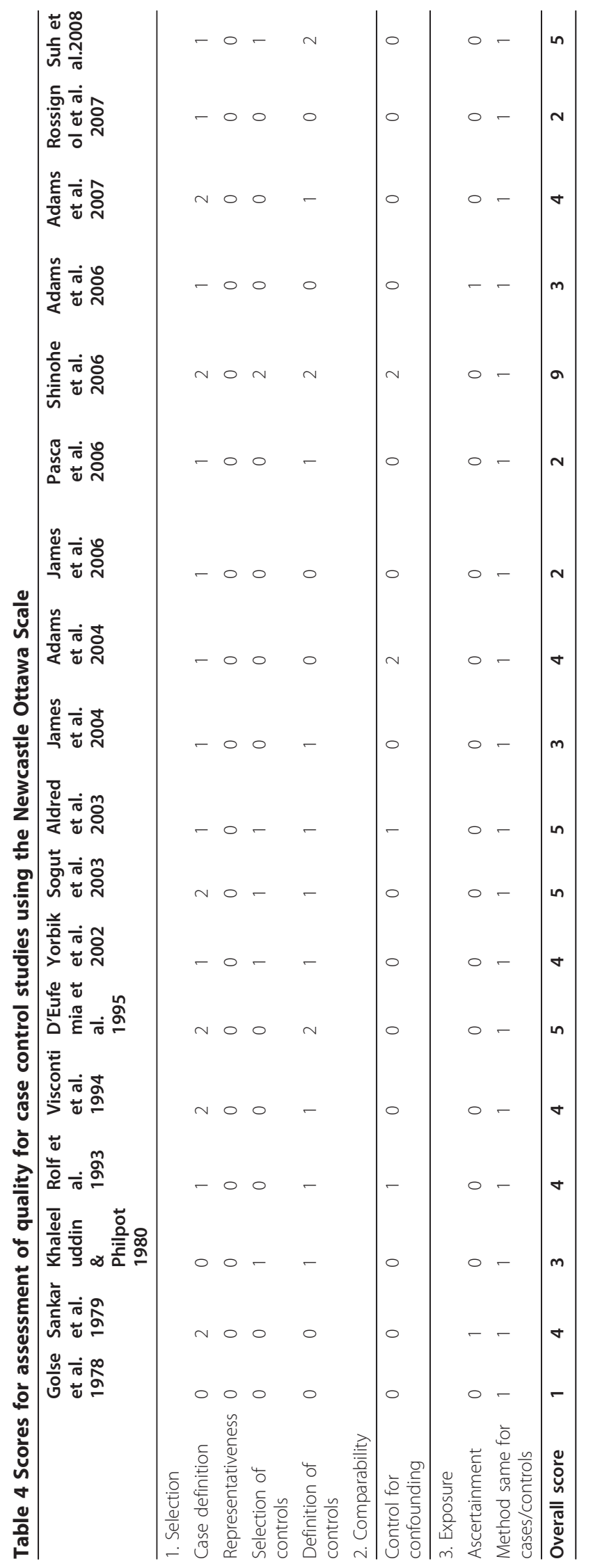




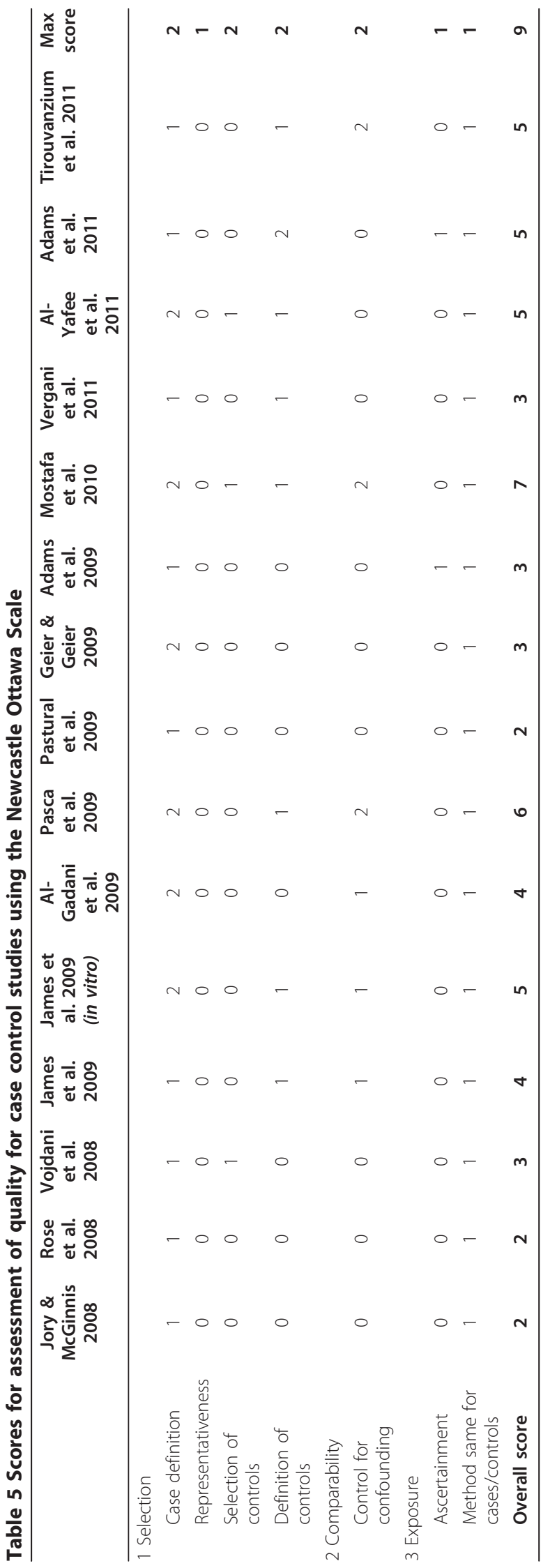


Table 6 Scores for assessment of quality for genetic studies the Newcastle Ottawa Scale

\begin{tabular}{|c|c|c|c|c|c|c|c|}
\hline & $\begin{array}{l}\text { Bowers et al. } \\
2011\end{array}$ & $\begin{array}{l}\text { Ming et al. } \\
2010\end{array}$ & $\begin{array}{l}\text { Buyske et al. } \\
2006\end{array}$ & $\begin{array}{l}\text { James et al. } \\
2006\end{array}$ & $\begin{array}{l}\text { Rose et al. } \\
2006\end{array}$ & $\begin{array}{l}\text { Serajee } \\
2004\end{array}$ & $\begin{array}{l}\text { Max } \\
\text { Score }\end{array}$ \\
\hline \multicolumn{8}{|l|}{1 Selection } \\
\hline Case definition & 2 & 2 & 1 & 1 & 1 & 2 & 2 \\
\hline Representativeness & 0 & 0 & 0 & 0 & 0 & 0 & 1 \\
\hline Selection of controls & trios & trios & trios & 0 & 0 & trios & 2 \\
\hline Definition of controls & $n / a$ & $\mathrm{n} / \mathrm{a}$ & $\mathrm{n} / \mathrm{a}$ & 0 & 0 & $\mathrm{n} / \mathrm{a}$ & 2 \\
\hline \multicolumn{8}{|l|}{2 Comparability } \\
\hline Control for confounding & $n / a$ & $n / a$ & $n / a$ & 0 & 0 & $\mathrm{n} / \mathrm{a}$ & $n / a$ \\
\hline \multicolumn{8}{|l|}{3 Exposure } \\
\hline Ascertainment & 0 & 0 & 0 & 0 & 0 & 0 & 1 \\
\hline $\begin{array}{l}\text { Method same cases/ } \\
\text { controls }\end{array}$ & 1 & 1 & 1 & 1 & 1 & 1 & 1 \\
\hline \multicolumn{8}{|l|}{4 Genetics } \\
\hline HW equilibrium & 1 & 0 & 1 & 1 & 1 & 1 & 1 \\
\hline Power calculations & $\mathrm{n} / \mathrm{a}$ & 0 & 1 & 0 & 0 & 1 & 1 \\
\hline $\begin{array}{l}\text { Control multiple } \\
\text { comparisons }\end{array}$ & 0 & 0 & 0 & 0 & 1 & 1 & 1 \\
\hline Population stratification & $n / a$ & $n / a$ & 0 & 0 & 0 & $n / a$ & 1 \\
\hline Overall score & 4 & 3 & 4 & 3 & 4 & 6 & 13 \\
\hline
\end{tabular}

reported significantly lower levels of GSH (by 32\%) and higher levels of GSSG (by 66\%) in plasma of children with autistic disorder compared to controls, together with significantly lower homocysteine and cysteine levels, while cystathione levels were significantly higher and cysteinyl-glycine levels were not significantly different [47]. These findings confirm those of an earlier pilot study by the same researchers with the exception that cystathione was found to be lower in children with autistic disorder in the pilot study [46], as well as a later study by the same research group which focussed on a subgroup of children with autistic disorder who had abnormal methylation and/or GSH:GSSG [48].

Plasma homocysteine levels for the above studies [46-48] showed that there was no statistically significant difference between children with autistic disorder and controls which has been replicated by a number of other research groups for children with autistic disorder [59,60,82], PDD-
NOS and Asperger's syndrome [60] as well as a mixed sample of children with autism spectrum disorders [77]. The only study to report a significant increase in plasma homocysteine in children with autistic disorder [74] was not replicated by the same research group using a fasted sample [60]. Examination of statistical heterogeneity showed low heterogeneity overall $\left(\mathrm{I}^{2}=34 \%\right)$ and no heterogeneity between diagnostic subgroups $\left(\mathrm{I}^{2}=0 \%\right)$ (Figure 4). Meta-analysis resulted in a standardised mean difference (SMD) of -0.18 (95\%CI -0.46-0.10) across 199 cases and 185 controls using a random effects model. Data from James et al. 2009 was not included in the analysis because the cases were selected for low methylation ratio or GSH: GSSG, however, the data is presented in Figure 4.

Similarly, no significant difference was observed in plasma cystathione from children with autistic disorder, PDD-NOS, Asperger's Syndrome or mixed autism spectrum disorders $[46,60,77]$, although another study report

Table 7 Scores for assessment of risk of bias for intervention studies

\begin{tabular}{|c|c|c|c|c|c|}
\hline Risk of bias & Bertoglio et al. 2011 & James et al. 2009 & Adams et al. 2009 & Rossignol et al. 2007 & James et al. 2004 \\
\hline Randomisation & Uncertain & Open label & Uncertain & Open label & Open label \\
\hline Concealment of allocation & Low risk & Open label & Low risk & Open label & Open label \\
\hline Blinding & Low risk & Open label & Low risk & Open label & Open label \\
\hline Incomplete outcome data & High risk & Low risk & High risk & Low risk & Low risk \\
\hline Selective reporting & High risk & Low risk & High risk & Low risk & Low risk \\
\hline Overall score & 5 & 4 & 5 & 4 & 4 \\
\hline
\end{tabular}




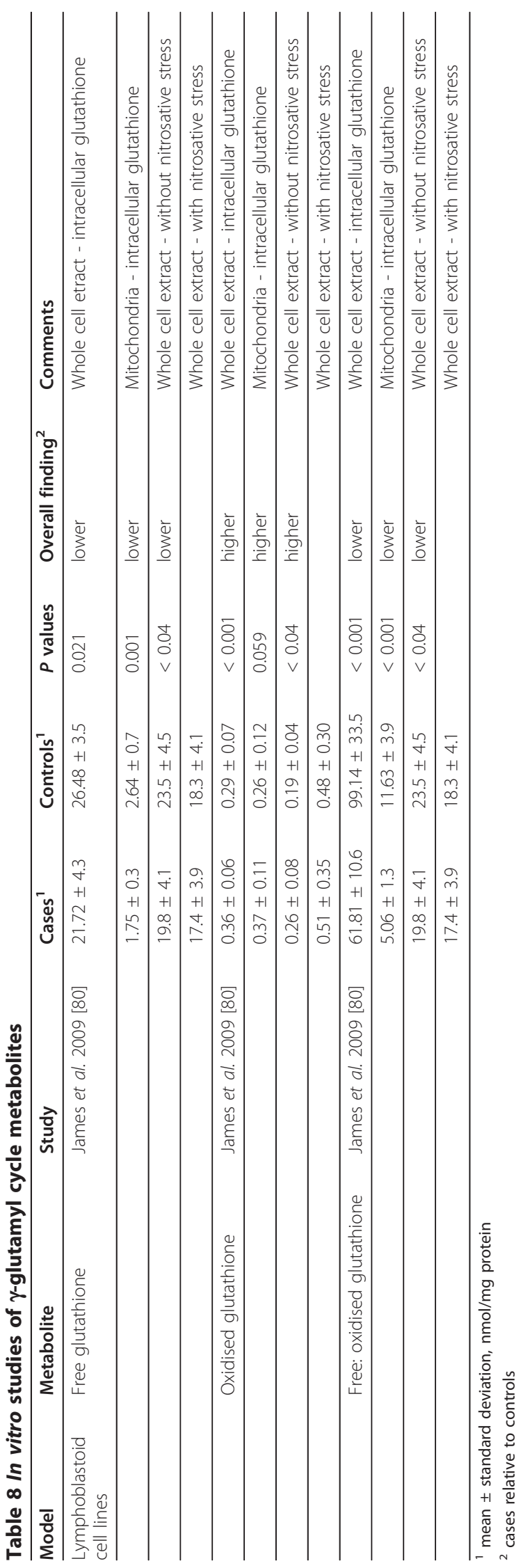




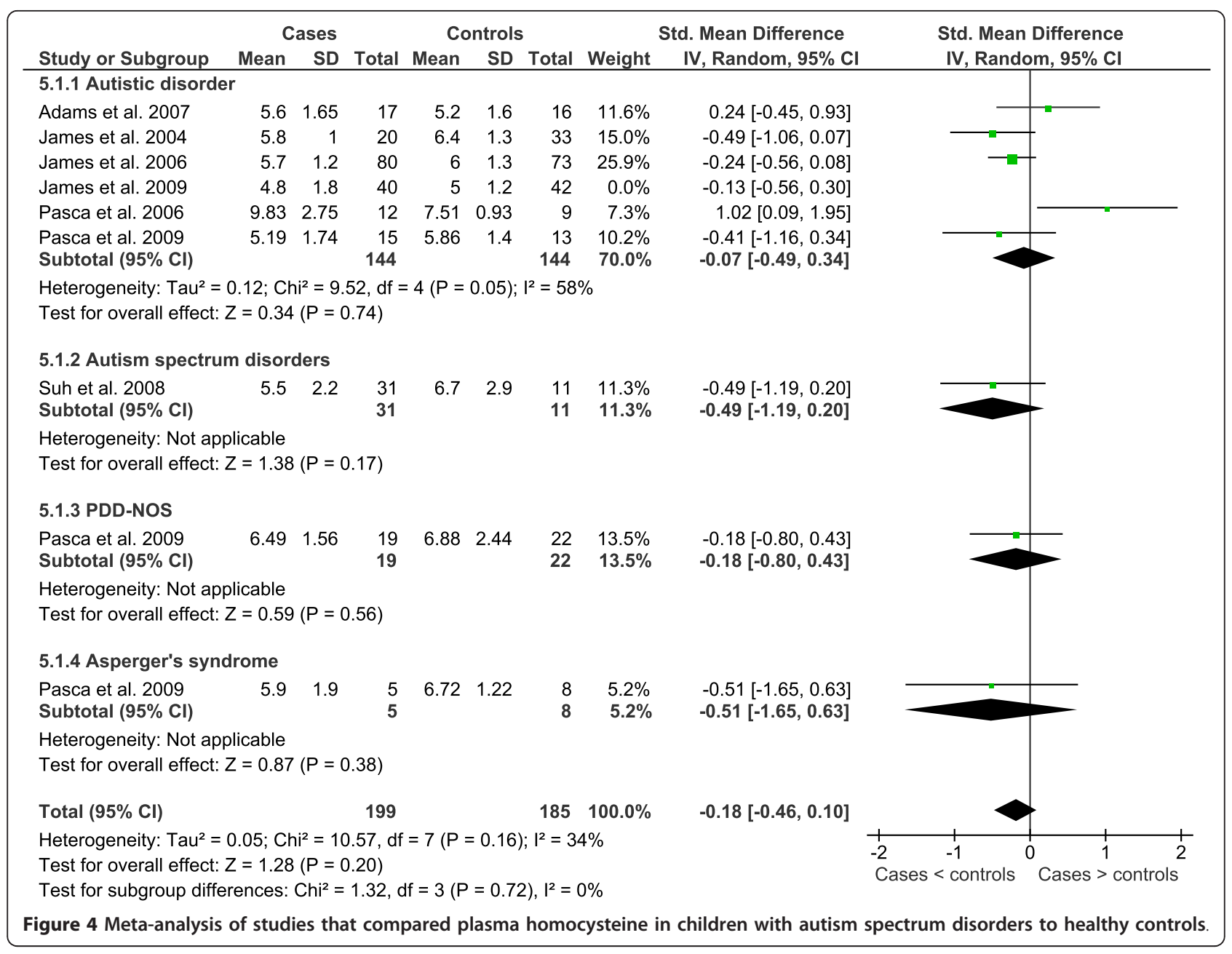

it to be significantly higher [47] in children with autistic disorder than controls (Figure 5). Examination of statistical heterogeneity showed that there was substantial overall heterogeneity $\left(\mathrm{I}^{2}=70 \%\right)$ with moderate heterogeneity between diagnostic subgroups $\left(\mathrm{I}^{2}=41.4 \%\right)$. It is hard to explain the heterogeneity given that two of the larger studies were conducted by the same research group using the same methodology $[46,47]$.

Serine is required for synthesis of cystathione from homocysteine. Four studies found no significant difference in serum or plasma serine levels between children and adults with or without autistic disorder, PDDNOS, Asperger's Syndrome or autism spectrum disorders (mixed sample) $[60,69,70,75]$, one study showed a trend towards a decrease in children with autistic disorder [60] and another reported significantly increased plasma serine in children with autism spectrum disorders [87] and significantly lower levels of serine were reported for platelet poor plasma in autism spectrum disorders [86]. Factors that may have contributed to the heterogeneity between studies include fasting status, differing laboratory methods and varied selection of controls as well as correction for multiple comparisons.

Studies showing that plasma cysteine is significantly lower in children with autistic disorder are dominated by one research group that published three studies (one in children with abnormal methylation or GSH:GSSG) [46-48] and their findings have been replicated by another research group [60]. The same study found no significant difference in plasma cysteine levels for children with PDDNOS or Asperger's Syndrome, as did a study comparing autism spectrum disorders (sample composition unknown) compared to controls [77]. Plasma cysteine was significantly lower in a study comprising 28 children with autistic disorder and 10 children with PDD-NOS [91]. Serum cysteine levels of children with autistic disorder compared to controls were not significantly different from controls [69]. Overall statistical heterogeneity for plasma cysteine was considerable $\left(\mathrm{I}^{2}=92 \%\right)$ and low to moderate between diagnostic subgroups $\left(\mathrm{I}^{2}=39.8 \%\right)$. Again, factors that may have led to the high level of heterogeneity 


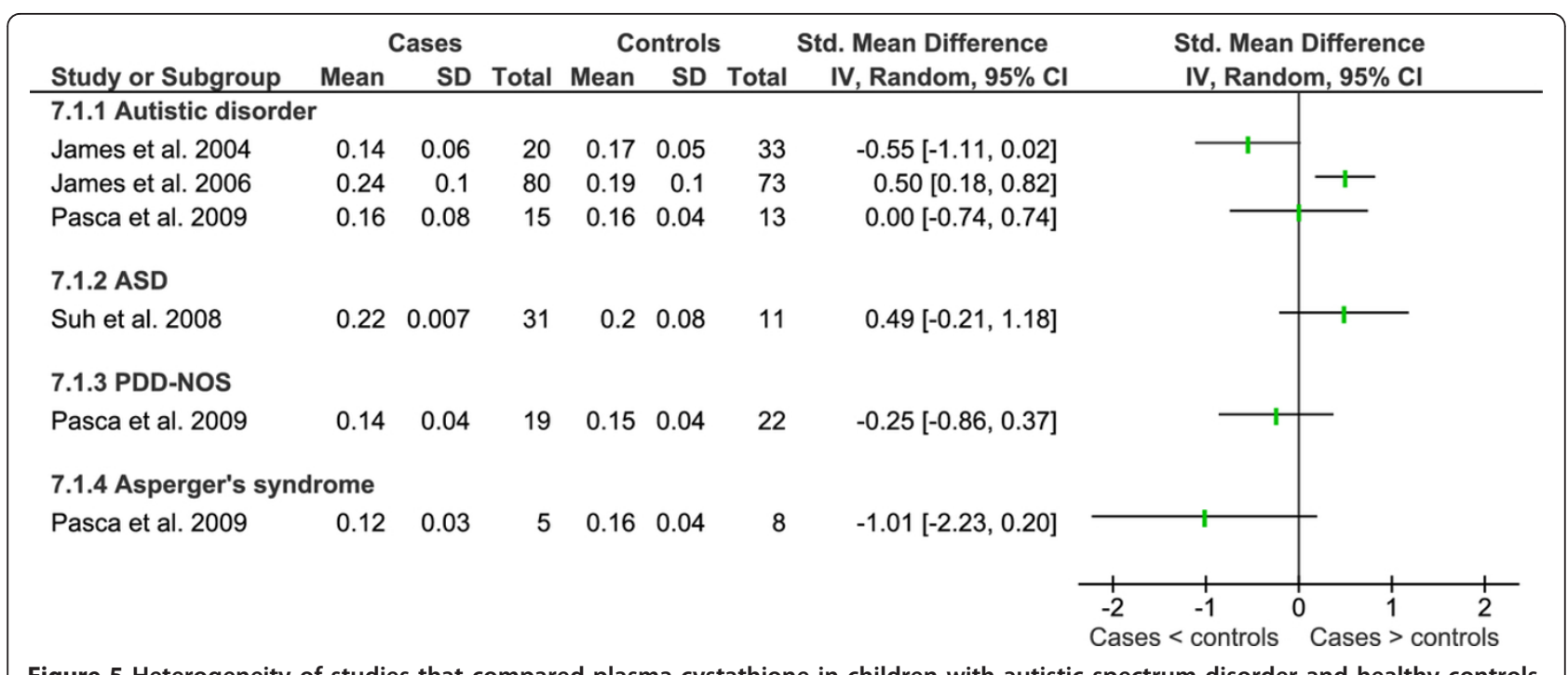

Figure 5 Heterogeneity of studies that compared plasma cystathione in children with autistic spectrum disorder and healthy controls.

between studies include fasting status, differing laboratory methods and varied selection of controls.

A significant decrease in plasma total glutathione (tGSH) reported in four studies from the one research group in children with autistic disorder compared to controls $[46-48,50]$ have been confirmed by another two research groups with respect to autistic disorder $[81,82]$ as well as study of low functioning children with autism spectrum disorders [85] (Figure 7). Reduced glutathione has also been reported to be lower in the plasma of children with autism spectrum disorders [87,91]. In contrast, no significant difference for plasma tGSH [77] or erythrocyte tGSH [65] was reported for autism spectrum disorders (mixed diagnoses). The later study compared cases to an adult reference range while noting that the paediatric range is lower. Whole blood tGSH was reported to be lower in autistic disorder but not significantly different for PDD-NOS or Asperger's Disorder [60]. Overall statistical heterogeneity was substantial for plasma tGSH $\left(\mathrm{I}^{2}=93 \%\right)$ however there was no statistical heterogeneity between diagnostic sub-groups $\left(\mathrm{I}^{2}=0 \%\right)$. Varying definition of cases and controls, laboratory and analytical methods may account for the range of heterogeneity.

The same major research group published four studies showing a significant increase in plasma oxidised glutathione in autistic disorder $[46-48,50]$ which has been

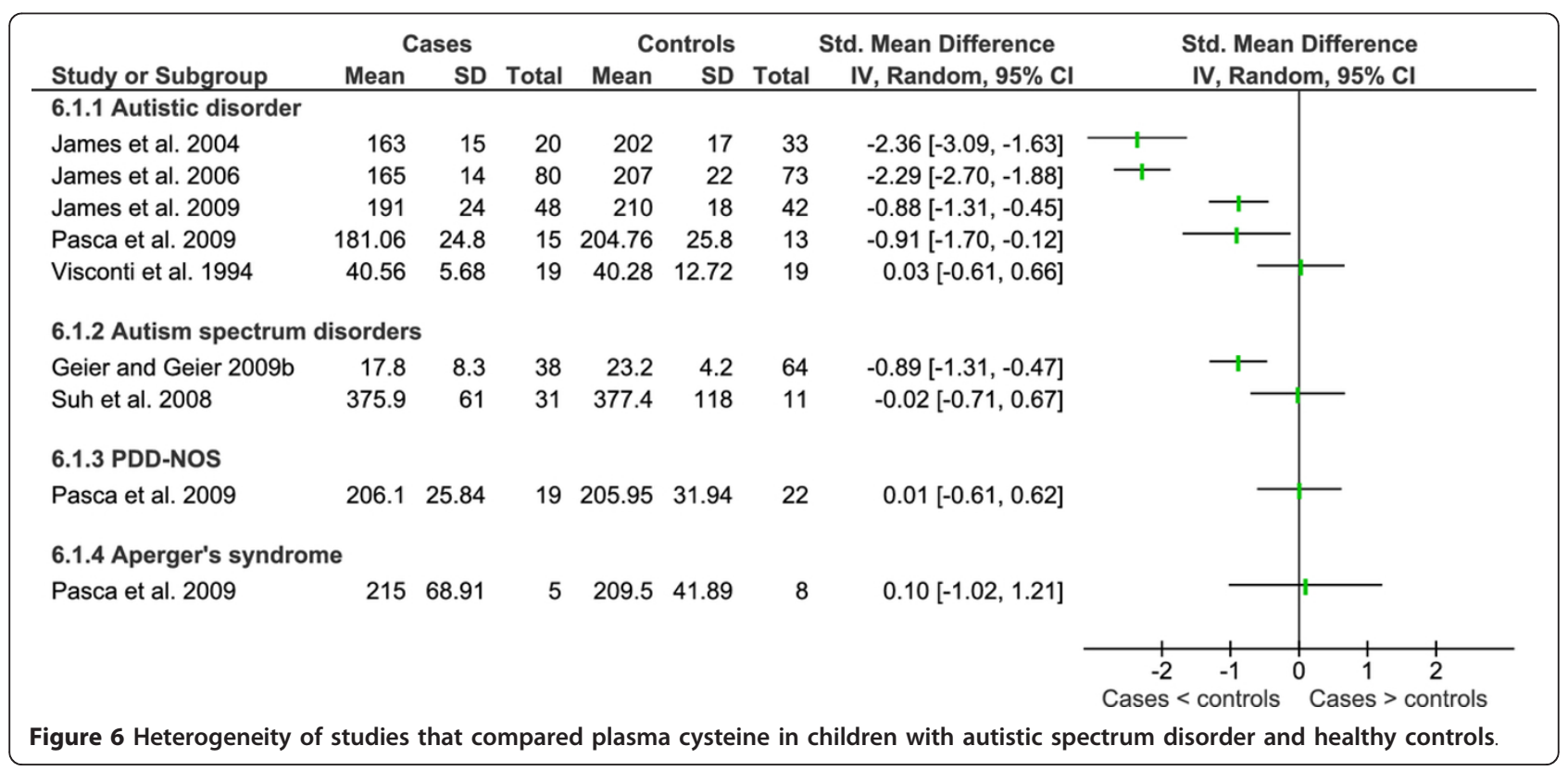




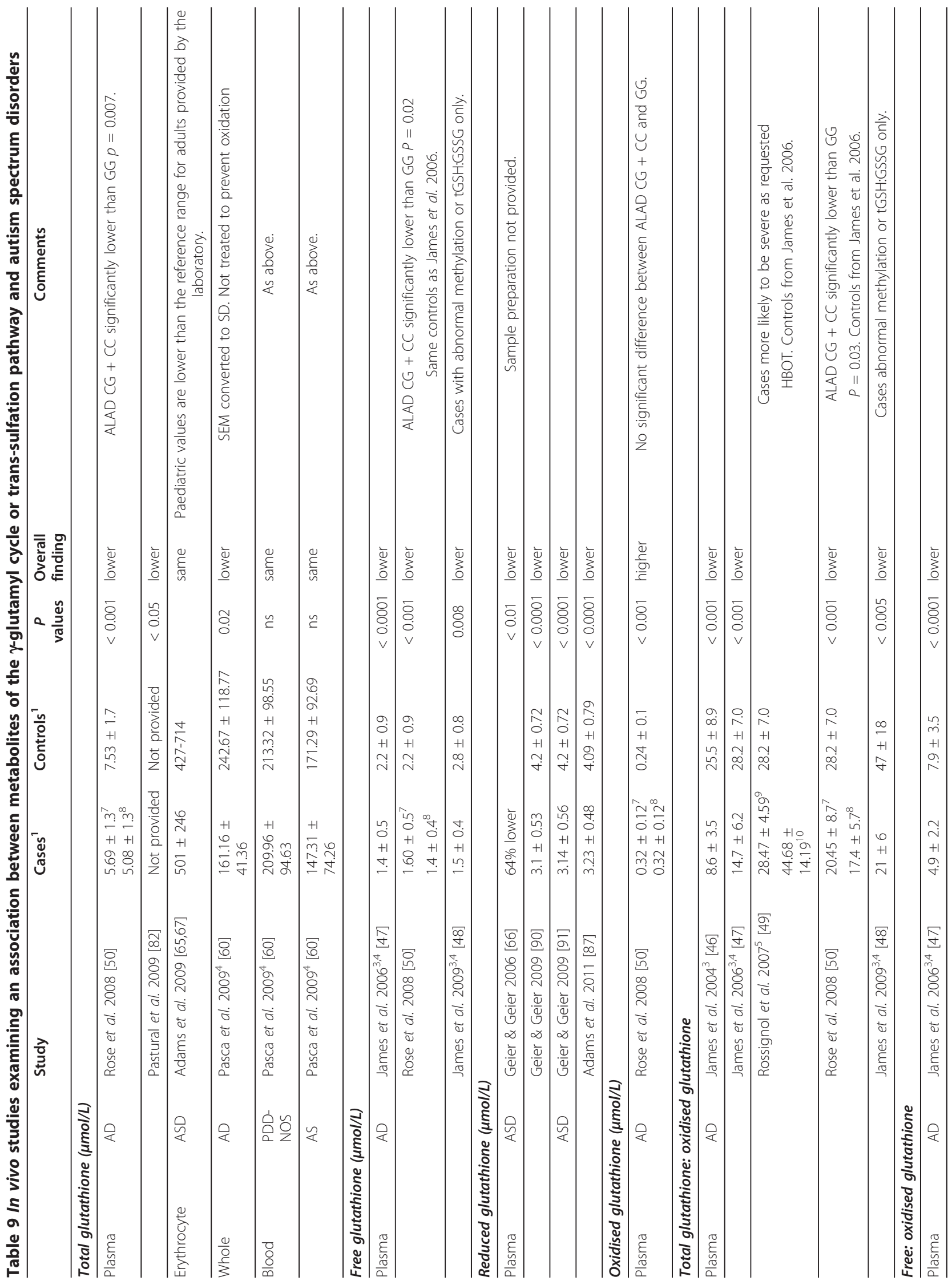




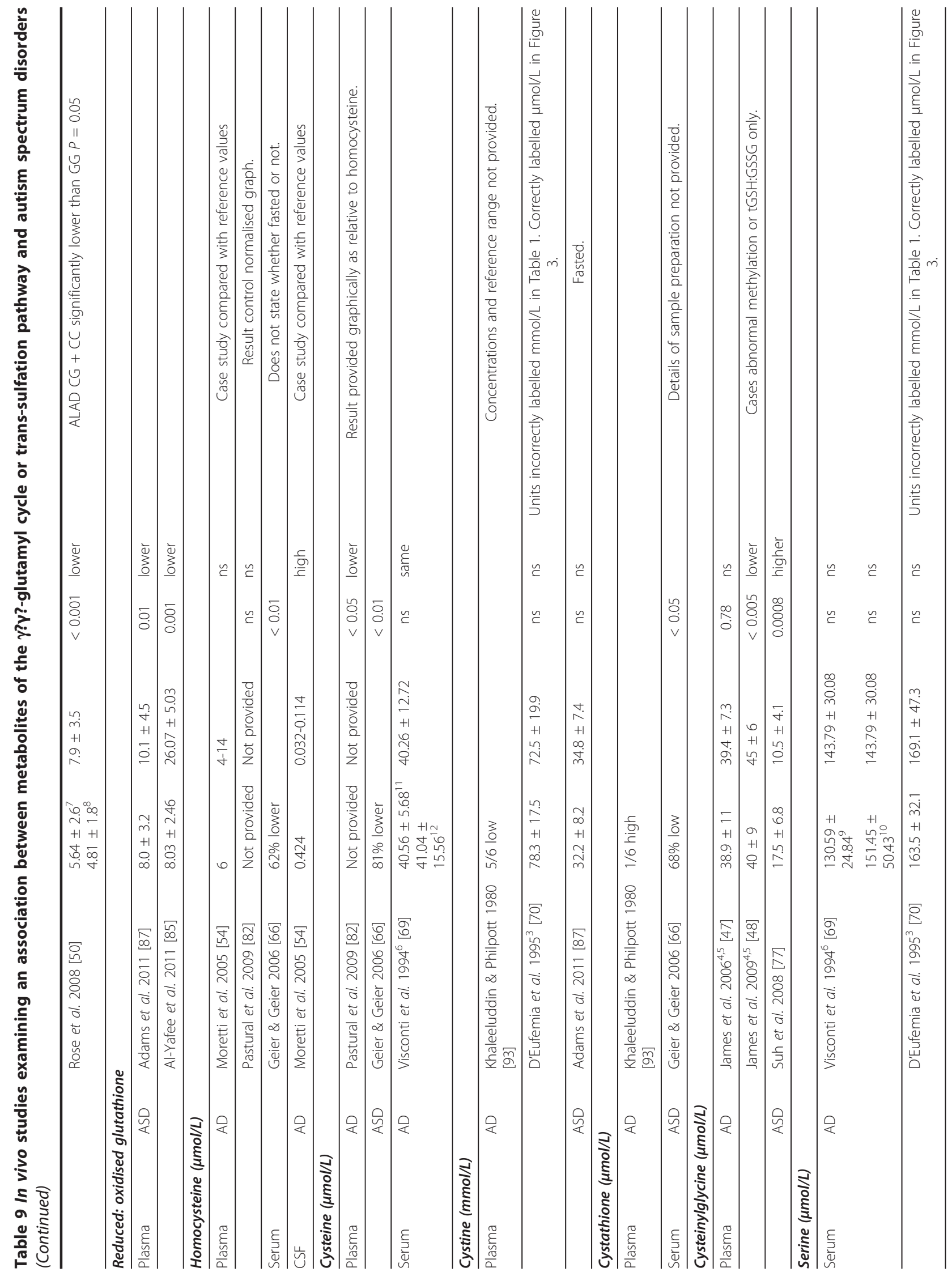




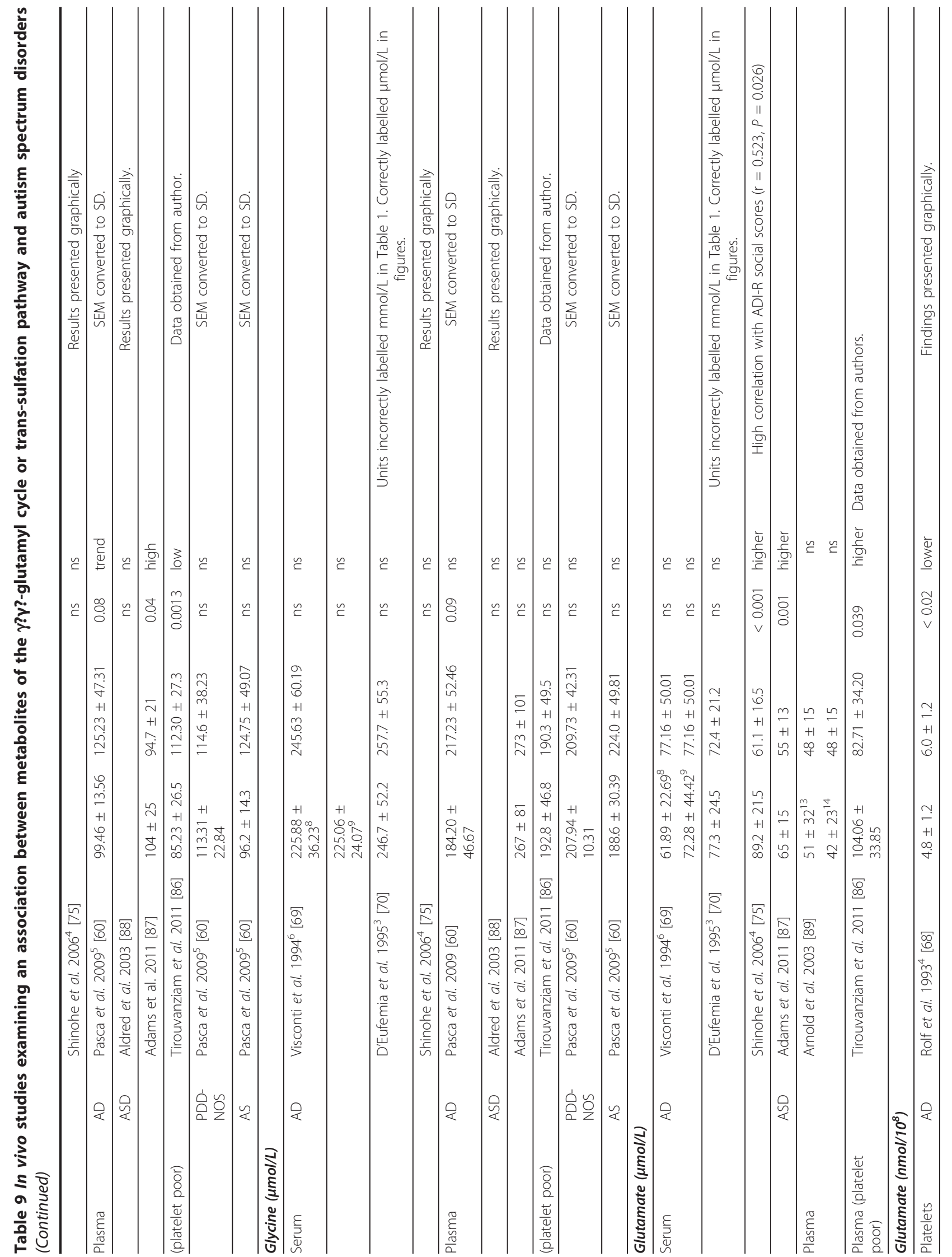




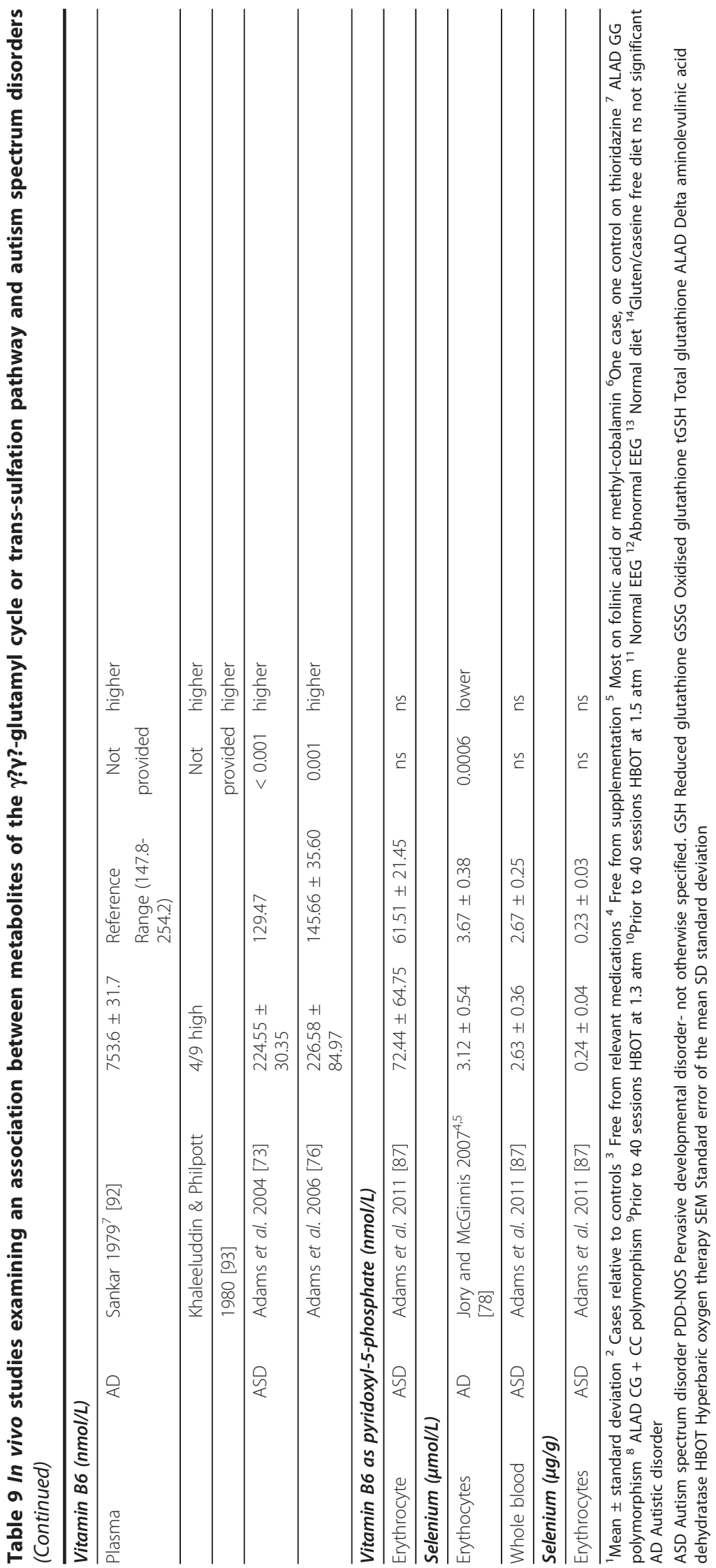




\begin{tabular}{|c|c|c|c|c|c|c|c|c|c|}
\hline \multirow[b]{2}{*}{ Study or Subgroup } & \multicolumn{3}{|c|}{ Case } & \multicolumn{2}{|c|}{ Control } & \multicolumn{2}{|r|}{ Std. Mean Difference } & \multirow{2}{*}{\multicolumn{2}{|c|}{$\begin{array}{l}\text { Std. Mean Difference } \\
\text { IV, Random, } 95 \% \mathrm{CI}\end{array}$}} \\
\hline & Mean & SD & Total & Mean & SD & Total & IV, Random, $95 \% \mathrm{CI}$ & & \\
\hline \multicolumn{10}{|l|}{ 1.1.1 Autistic disorder } \\
\hline Al-Gadani et al. 2009 & 73.67 & 26.51 & 30 & 101.46 & 37.6 & 30 & $-0.84[-1.37,-0.31]$ & + & \\
\hline James et al. 2004 & 4.1 & 0.5 & 20 & 7.6 & 1.4 & 33 & $-3.00[-3.81,-2.19]$ & $\rightarrow$ & \\
\hline James et al. 2006 & 5.1 & 1.2 & 80 & 7.53 & 1.7 & 73 & $-1.66[-2.02,-1.29]$ & + & \\
\hline James et al. 2009 & 5.4 & 1.3 & 40 & 7.5 & 1.8 & 42 & $-1.32[-1.80,-0.84]$ & + & \\
\hline \multicolumn{10}{|c|}{ 1.1.2 Autism spectrum disorders } \\
\hline Al-Yaffee et al. 2011 & 4.46 & 0.33 & 20 & 8.28 & 1.03 & 20 & $-4.90[-6.18,-3.61]$ & $\longrightarrow$ & \\
\hline \multirow[t]{2}{*}{ Suh et al. 2008} & 7.3 & 2.3 & 31 & 7.7 & 2.1 & 11 & $-0.17[-0.86,0.51]$ & & \\
\hline & & & & & & & & $\begin{array}{cc}-4 & -2 \\
\text { Cases }<\text { controls }\end{array}$ & $\begin{array}{cc}2 & 4 \\
\text { Cases }>\text { controls }\end{array}$ \\
\hline
\end{tabular}

replicated by a further two research groups for autism spectrum disorders $[87,91]$ (Figure 8). Overall statistical heterogeneity was substantial $\left(\mathrm{I}^{2}=67 \%\right)$, however, there was no statistical heterogeneity between diagnostic subgroups $\left(\mathrm{I}^{2}=0 \%\right)$. Meta-analysis resulted in a SMD of 1.25 (95\% CI 0.87 - 1.62) across 203 cases and 184 controls using a random effects model. As stated above, data from James et al. 2009 was not included in the analysis but is included in the tables accompanying the Figure.

The same research group published 5 studies reporting significantly lower plasma tGSH:GSSG ratios in children with autistic disorder [46-50]. The same controls were used for three of the studies $[47,49,50]$. One of these studies tGSH and tGSH:GSSG were significantly lower (by $10.7 \%$ and $14.9 \%$ respectively) in children with autism who were heterozygous or homozygous for the delta aminolevulinic acid dehydratase (ALAD) 177 GC mutation, whereas there was no difference in GSSG [50]. This polymorphism is found in the heme biosynthesis pathway where it has been associated with altered toxicokinetics of lead levels and elevated blood levels of lead [100-102]. Three studies have shown that GSH:
GSSG is lower in children with autism spectrum disorders $[85,87,91]$ lending credence to the original findings.

The findings for cysteinyl-glycine, a breakdown product of glutathione, were inconsistent. Initially it was reported that there was no significant difference in cysteinyl-glycine in children with autistic disorder compared to controls [47]. A later study by the same research group was limited to children with abnormal methylation or GSH:GSSG showed that it had a significantly lower level in autistic disorder than in controls [48], however, a subsequent study of children with autism spectrum disorders showed that it was significantly higher than in controls [77]. Differences in inclusion criteria, laboratory methods and control of confounding variables may account for the difference in the findings.

Finally, the relationship between GSH and the immune system was clearly demonstrated in a large study which showed that children with autistic disorder universally have lower natural killer cell activity in peripheral mononuclear cells than those without the disorder which correlated with low intracellular levels of GSH as shown in Table 10 [79]. Furthermore, when

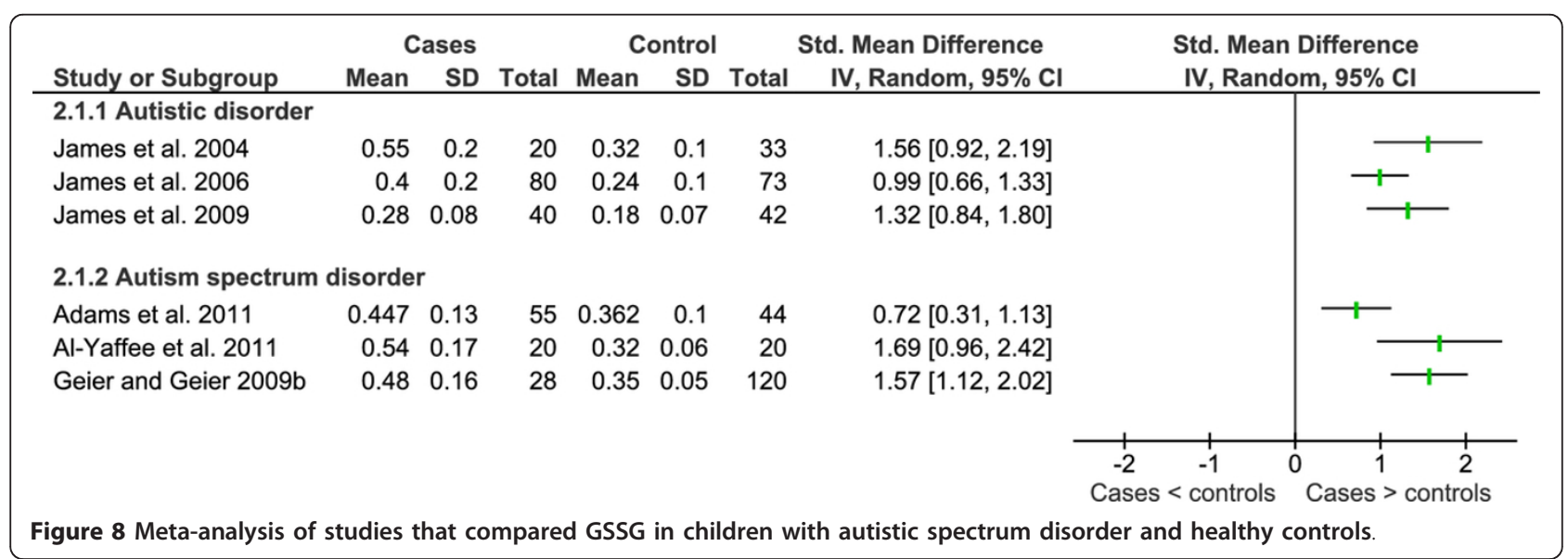


Table 10 Correlation between NK cell activity and reduced glutathione in peripheral blood mononuclear cells obtained from children with autistic disorder

\begin{tabular}{lllll}
\hline Study & $\begin{array}{l}\text { NK Activity } \\
(\text { LU) }\end{array}$ & $\begin{array}{l}\text { GSH }\left(\mathbf{n g} / \mathbf{3} \times \mathbf{1 0}^{\mathbf{6}}\right. \\
\text { PBMCs) }\end{array}$ & Significance & Finding \\
\hline $\begin{array}{l}\text { Vojdani et al. } \\
2008\end{array}$ & $0-10$ & $610 \pm 286$ & $\begin{array}{l}\text { ANOVA F }=3.99, P< \\
0.05\end{array}$ & Direct correlation between cellular levels of reduced glutathione and \\
NK lytic activity.
\end{tabular}

NK Natural killer cells LU Lytic units GSH reduced glutathione ng nanograms PBMCs Peripheral blood mononuclear cells ANOVA One way analysis of variance

GSH was added to the culture medium, natural killer cell activity increased more in lymphocytes obtained from children with low natural killer cell activity than those with normal activity. Corresponding data were not provided for control children.

Glycine and glutamine are key compounds for the biosynthesis of glutathione obtained through dietary sources. Eight studies showed no significant difference in serum or plasma glycine in children with autistic disorder $[60,69,70,75]$, autism spectrum disorders (mixed diagnoses) [86-88] PDD-NOS or Asperger's Syndrome compared to controls [60]. There was no statistical heterogeneity overall $\left(\mathrm{I}^{2}=0\right)$ or between diagnoses $\left(\mathrm{I}^{2}=0\right)$ for plasma glycine. The data was not pooled because there were only two studies for plasma and two for serum with data in a suitable form to combine.

In contrast the findings for glutamine were inconsistent with two studies reporting no significant difference in serum glutamine in children with autistic disorder compared with controls $[69,89]$, a later study reporting a significant decrease in platelet glutamine in children with autistic disorder [68] and further studies that reported serum glutamate to be significantly higher in adults with autistic disorder [75] and children with autism spectrum disorders (mixed diagnoses) than controls [87].

Of the six studies that measured co-factors of the $\gamma$ glutamyl cycle or trans-sulphuration pathway, five studies showed elevated levels of vitamin B6 in children with autistic disorder or autism spectrum disorders compared to controls $[73,76,87,92,93]$, one showed a decrease in erythrocyte selenium in children with autistic disorder [78] and another showed no change in whole blood selenium in children with an autism spectrum disorder compared to controls [87].

\section{Intervention studies}

The findings of the six studies that report the outcome of interventions in autism focussed on normalising abnormalities in $\gamma$-glutamyl cycle or trans-sulphuration pathway metabolites $[46,48,49,54,64]$ are presented in Table 11. An initial pilot study showed that supplementation of children with autistic disorder with $800 \mu \mathrm{g}$ folinic acid and 1,000 $\mu$ g betaine per day for two months normalised homocysteine levels and improved GSH: GSSG [46]. The addition of $75 \mu \mathrm{g} / \mathrm{kg}$ methyl-cobalamin injected twice weekly for one month further normalised GSH:GSSG. The same researchers conducted a larger intervention in 42 children with autistic disorder who had evidence of reduced methylation capacity or GSH: GSSG in which they were supplemented with folinic acid and methyl-cobalamin for 3 months [48]. The new regimen, which used half the dose of folinic acid of that used in the pilot study, resulted in significant increases in metabolites of the trans-sulphuration pathway as well as GSH:GSSG, although they remained below those of the control children. Objective behavioural measures showed an improvement, although all participants were still well below normal (data not published).

Recently, a double blinded randomised controlled trial was published in which participants were administered either methyl-cobalamin or placebo for 6 weeks and then their treatment switched without washout for a further 6 weeks [64]. Overall, there was no significant change in GSH, GSH:GSSG or behaviour. Thirty percent of participants, however, showed a significant improvement in objective behavioural measures which correlated with improved plasma GSH and GSH:GSSG levels. Interpretation of the findings is difficult because data was only provided for the 'responder' subgroup and this did not include standard deviations or units for plasma GSH or GSH:GSSG, nor did it state whether the GSH values reported in Figure 4 of their paper represented tGSH or reduced glutathione. Furthermore, data showing whether 'responders' had lower baseline concentrations of GSH or GSH:GSSG were not provided.

Additionally, a case report of a child with autistic disorder and cerebral folate deficiency showed the normalisation of low cerebral spinal fluid homocysteine following 2 weeks supplementation with $0.5 \mathrm{mg}$ folinic acid $/ \mathrm{kg} /$ day increasing to $1.0 / \mathrm{kg} /$ day for 3 months [54]. Finally, a 40 session trial of hyperbaric oxygen therapy showed that it has no effect on plasma GSH:GSSG in children with autistic disorder [49] and, as discussed above, incomplete data and selective reporting make it hard to interpret the findings of a randomised trial of topical glutathione before chelation [65]. 
Table 11 In vivo studies involving interventions directed at normalising $\gamma$-glutamyl cycle or trans-sulfation pathway metabolites

\begin{tabular}{|c|c|c|c|c|c|}
\hline Study & Intervention & Dose \& duration & Study size & Findings & Comments \\
\hline \multicolumn{6}{|c|}{ Interventions involving folate cycle metabolites } \\
\hline $\begin{array}{l}\text { Bertoglio } \\
\text { et al. } \\
2010[64]\end{array}$ & $\begin{array}{l}\text { Methyl- } \\
\text { cobalamin }\end{array}$ & $\begin{array}{l}64.5 \mu \mathrm{g} / \mathrm{kg} \text { methyl-cobalamin or } \\
\text { placebo injected every third day } \\
6 \text { wks washout period). }\end{array}$ & $\begin{array}{l}32+\text { cases } \\
\text { started the } \\
\text { trial of } \\
\text { which } 30 \\
\text { finished. }\end{array}$ & $\begin{array}{l}\text { Overall, no significant difference in } \\
\text { GSH, GSH: GSSG or } \\
\text { behaviouraloutcomes. } \uparrow \text { GSH, } \\
\uparrow G S H: G S S G \text { and improved } \\
\text { behavioural outcomes in } 9 / 30 \\
\text { children. }\end{array}$ & $\begin{array}{l}\text { Primary outcome behavioural } \\
\text { response. Findings for GSH and } \\
\text { tGSH:GSSG presented as bar charts } \\
\text { for responder group only. } \\
\text { Dispersion and units not provided. }\end{array}$ \\
\hline $\begin{array}{l}\text { James et } \\
\text { al. } 2009 \\
{[48]}\end{array}$ & $\begin{array}{l}\text { Folinic acid } \\
+ \text { methyl- } \\
\text { cobalamin }\end{array}$ & $\begin{array}{l}400 \mu \mathrm{g} \text { folinic acid bd }+75 \mu \mathrm{g} / \\
\mathrm{kg} \text { methyl-cobalamin injected } \\
\text { every third day } 3 \text { mo. }\end{array}$ & $\begin{array}{l}48 \text { cases } \\
\text { selected for } \\
\text { low SAM: } \\
\text { SAH or } \\
\text { GSH: GSSG. }\end{array}$ & $\begin{array}{l}\uparrow \text { homocysteine, } \uparrow \text { cystathione } \uparrow \\
\text { cysteine, } \uparrow \mathrm{tGSH} \& \uparrow \mathrm{tGSH}: \mathrm{GSSG} \text {. }\end{array}$ & $\begin{array}{l}\text { Excluded } 26 \% \text { of cases because } \\
\text { normal SAM: SAH and/or tGSH: } \\
\text { GSSG. Following the intervention, } \\
\text { tGSH:GSSG was still significantly } \\
\text { lower in cases than controls. There } \\
\text { was no change in SAM or SAH } \\
\text { levels. }\end{array}$ \\
\hline \multirow[t]{3}{*}{$\begin{array}{l}\text { James et } \\
\text { al. } 2004 \\
{[46]}\end{array}$} & $\begin{array}{l}\text { Folinic acid } \\
+ \text { betaine }\end{array}$ & $\begin{array}{l}800 \mu \mathrm{g} \text { folinic acid }+1,000 \mu \mathrm{g} \\
\text { betaine bd } 3 \text { mo. }\end{array}$ & 8 cases & $\begin{array}{l}\uparrow \text { homocysteine, } \uparrow \text { cystathione } \uparrow \\
\text { cysteine, } \uparrow \mathrm{tGSH}, \uparrow \mathrm{tGSH}: \mathrm{GSSG}, \\
\downarrow S A H \& \downarrow \text { adenosine }\end{array}$ & $\begin{array}{l}\text { Improved but did not normalise } \\
\text { tGSH and GSSH. }\end{array}$ \\
\hline & $\begin{array}{l}\text { Folinic acid } \\
+ \text { betaine }+\end{array}$ & As above + $75 \mu \mathrm{g} / \mathrm{kg}$ methyl- & 8 cases & $\uparrow$ homocysteine, & Normalised tGSH \& tGSH: \\
\hline & $\begin{array}{l}\text { methyl- } \\
\text { cobalamin }\end{array}$ & $\begin{array}{l}\text { cobalamin injected twice weekly } \\
1 \text { mo. }\end{array}$ & & $\begin{array}{l}\uparrow c y s t a t h i o n i n e, ~ \uparrow c y s t e i n e, ~ \uparrow t G S H, \\
\uparrow t G S H: \text { GSSG, } \downarrow \text { GSSG }\end{array}$ & $\begin{array}{l}\text { GSSG. Improved but did not } \\
\text { normalise GSSG. }\end{array}$ \\
\hline $\begin{array}{l}\text { Moretti et } \\
\text { al. } 2005 \\
{[54]}\end{array}$ & Folinic acid & $\begin{array}{l}0.5 \mathrm{mg} / \mathrm{kg} / \mathrm{d} \text { folinic acid for } 2 \mathrm{wk} \text {, } \\
1.0 \mathrm{mg} / \mathrm{kg} / \mathrm{d} \text { thereafter } 3 \mathrm{mo} \text {. }\end{array}$ & 1 case & $\begin{array}{l}\text { Normalised }(\downarrow) \text { cerebral spinal } \\
\text { fluid homocysteine. }\end{array}$ & \\
\hline
\end{tabular}

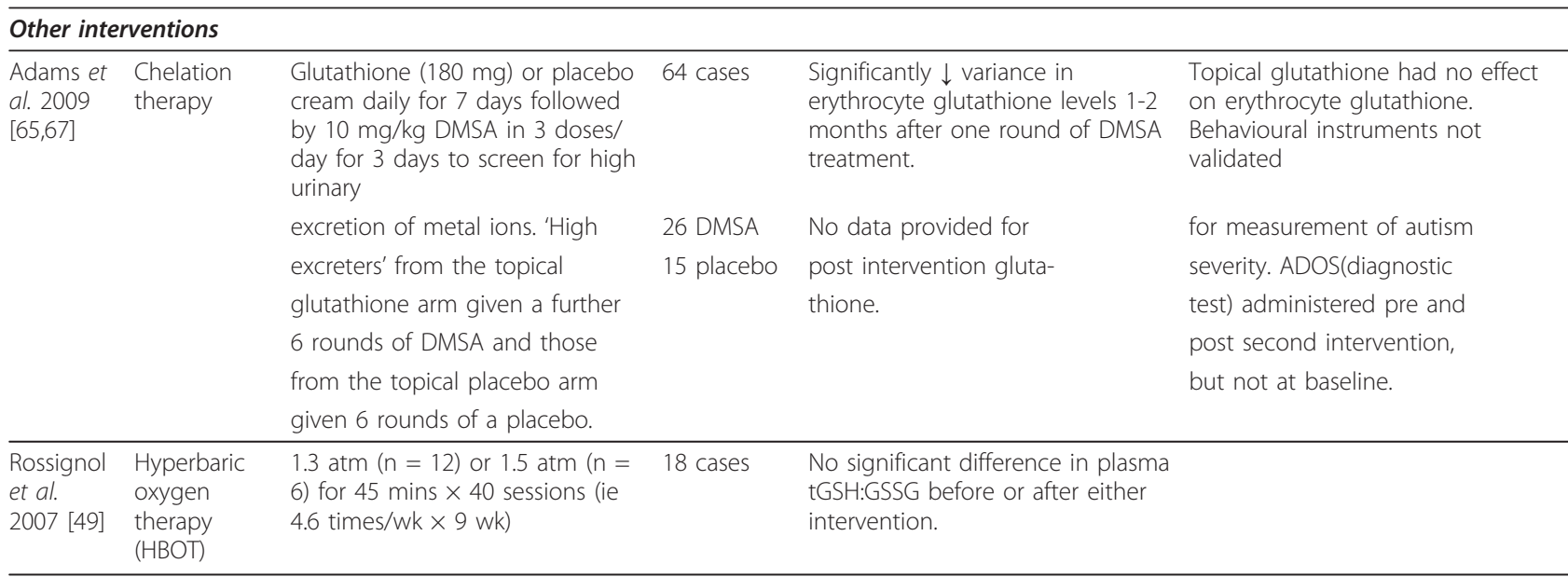

SAM s-adenosyl-methionine SAH s-adenosyl-homocysteine tGSH total glutathione GSSH Oxidised glutathione bd twice daily DMSA dimercaptosuccinic acid ADOS autism diagnostic observation schedule

\section{Genetic studies of the $\gamma$-glutamyl cycle and trans- sulphuration pathway}

The six studies that presented data on genetic polymorphisms of the $\gamma$-glutamyl cycle or trans-sulphuration pathway are summarised in Table 12 . The best powered of these studies examined genetic variation in 42 genes (308 single nucleotide polymorphisms (SNPs)) related to glutathione, including those coding for enzymes that use glutathione as a co-factor (not included in this review), in 318 families from the Autism Genetic Resource Exchange repository [87]. Several SNPs located in the genes for cystathionine $\gamma$-ligase $(\mathrm{CTH})$, alcohol dehydrogenase 5, GCL and glutaredoxin showed significant or suggestive associations with autism spectrum disorders. Interaction models confirmed a significant association between $\mathrm{CTH}$, glutaredoxin and glutaredoxin 3 and autism $(\mathrm{OR}=3.78$ (95\% CI 2.36-6.04).

The study found no association between any of the GST genes and autism [94]. This is in contrast to a previous study of case parent trios that found that homozygote cases for the GST-M*1 gene deletion (GST-M1*0) showed increased risk of autistic disorder [96] and a later case control study that reported a borderline association between the GST-M*1 gene deletion (GST-M1*0) and autistic disorder and a significant interaction between the GST-M1*0 deletion and the reduced folate carrier 80A > 


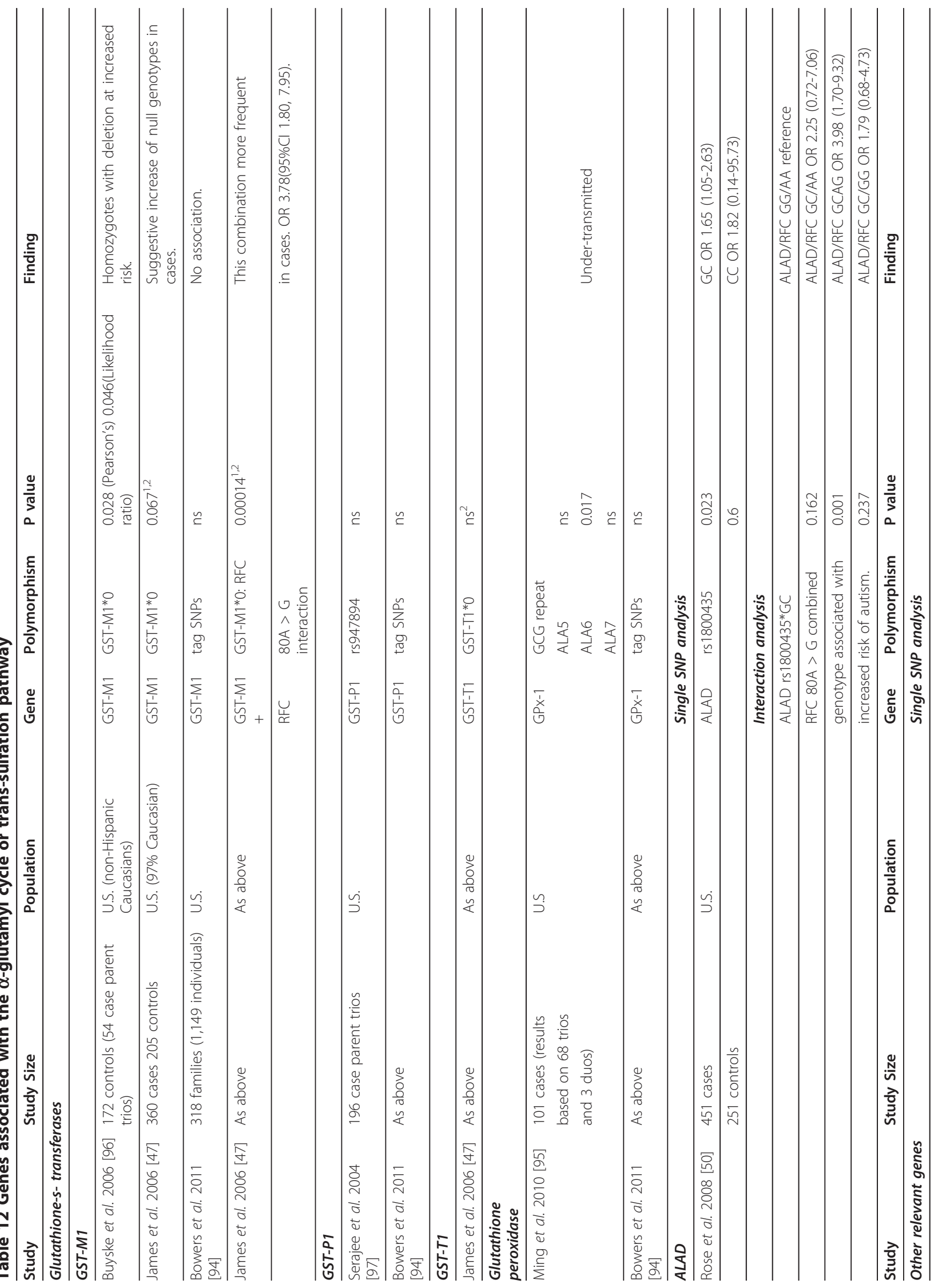




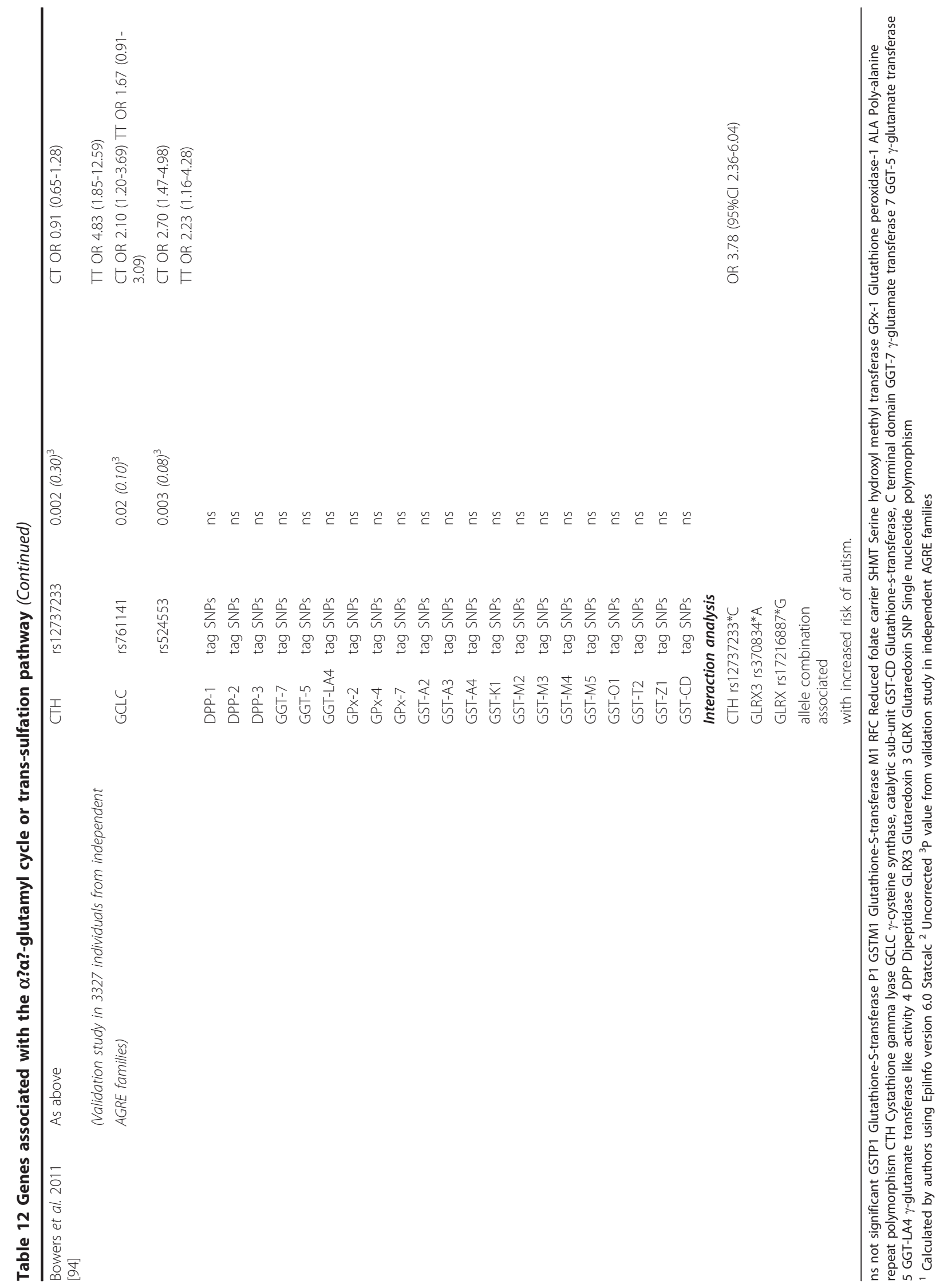


G [47]. Previous studies failed to find an association between GST-T1 [47] or GST-P1 and autism [97].

Ming et al. 2010 Found that a polyalanine repeat polymorphism in the GPx gene (GPx-1) was associated with autistic disorder [95]. Under-transmission of the variation encoding six alanine residues (ALA6) was observed in the families with autistic disorder, suggesting that this allele may be protective. The authors acknowledge that their interpretation is limited by inadequate knowledge of the function of the ALA alleles of GPx-1 gene.

\section{Studies of glutathione related enzyme activity}

As shown in Table 13 GPx-1 activity has been the subject of seven studies $[63,71,72,74,81,83,84]$. The findings were inconsistent in plasma where two studies reported higher activity in cases than controls $[72,81]$ and two reported lower activity [71,83]. A further four studies examined GPx-1 activity in erythrocytes. Of these, two reported lower activity [63,71] and two reported no significant difference between cases and controls $[74,84]$. No significant difference between cases and controls was reported for GPx-1 activity in platelets [63]. In addition, a recently published study showed that glutathione-S-transferase activity was significantly reduced in children with low functioning autism spectrum disorders and there was a trend towards lower activity of glutathione reductase [85].

\section{Discussion}

The findings of this systematic review support the assertion that children with autism spectrum disorders are more likely to have significantly lower tGSH and GSH and significantly increased GSSG, resulting in a significantly lower GSH:GSSG than children without autism. Our review show that although serum homocysteine and cystathione levels are not significantly different in children with autism spectrum disorders compared to those without, serum cysteine is significantly lower in autistic disorder (Figures 4, 5 and 6) which supports the assertion that cysteine production may be the rate limiting step in glutathione synthesis [31-34]. The lack of an association in other forms of autism spectrum disorders suggests that low cysteine may be associated with autism severity [60,77].

As no significant differences in serum homocysteine, cystathionine (Figures 4 and 5) or serine levels [60,69,70,75] were observed in children with autistic disorder compared to those without, it can be inferred that the low levels of cysteine may be caused by decreased cystathione lyase activity and/or increased utilisation of sulphate and/or taurine and/or lower dietary intake or absorption of cysteine in children with autistic disorder. An exploration of the functional significance of several SNPs in the gene for cystathione lyase associated with autistic disorder may shed light on this putative relationship [94].

It is worth noting that a reduction in total glutathione implies a problem with synthesis of glutathione, whereas a decrease in GSH implies an anomaly in GSH:GSSG. Both have been observed in autism spectrum disorders $[46-48,50,77,81,82,85,87,91]$. As the bioavailability of cysteine is the rate limiting factor for synthesis of GSH [31-34], the lower cysteine levels detected in serum of children with autistic disorder could be an important factor leading to the lower levels of GSH observed in many children with this condition [46-48,50,81,82]. While several studies examined GPx activity $[63,71,72,74,81,83,84]$ or its polymorphisms [94,95], only one examined glutathione reductase or glutathione-S-transferase activity [85].

The higher level of GSSG observed in the serum of many children with autism spectrum disorders [46-48, $50,85,87,91$ ] is likely to truly reflect increased oxidative stress as there is no significant difference in GPx-1 activity in serum or platelets $[63,84]$ and GPx-1 is significantly lower in the erythrocytes of children with autistic disorder compared to controls. As cysteine itself may have strong anti-oxidant properties, its lower concentration in children with autistic disorder may contribute to increased oxidation of GSH [47].

Glutathione synthesis also requires dietary glutamate and glycine. No difference in serum levels of glutamate has been reported between children with autistic disorder and controls $[69,70]$, however, it was significantly higher in adults with autistic disorder [75], the level being positively correlated with social functioning as measured by the autism diagnostic interview (ADI-R) [103] which is commonly used to evaluate the core symptoms of autism which may shed light on the significantly higher level detected in mixed samples of children with autism spectrum disorders $[86,87]$. In contrast, platelet glutamic acid was significantly lower in children with autistic disorder [68]. Platelet glutamate receptors have been shown to have heightened sensitivity in major depression, schizophrenia and other psychoses [104-106]. This relationship has not, however, been examined in autism spectrum disorders to date.

Serum and plasma glycine does not differ between children $[60,69,70,86,87]$ or adults [107] with and without autism spectrum disorders. As glycine acts as a powerful inhibitory neurotransmitter in the brain and spinal chord [108] and glycine transporters are differentially expressed throughout the CNS [109], it may be relevant for future studies of children with autism spectrum disorders to examine whether there are abnormalities in expression of glycine transporters in the CNS or in glycine transport across the choroid plexus in children with autism spectrum disorders. 


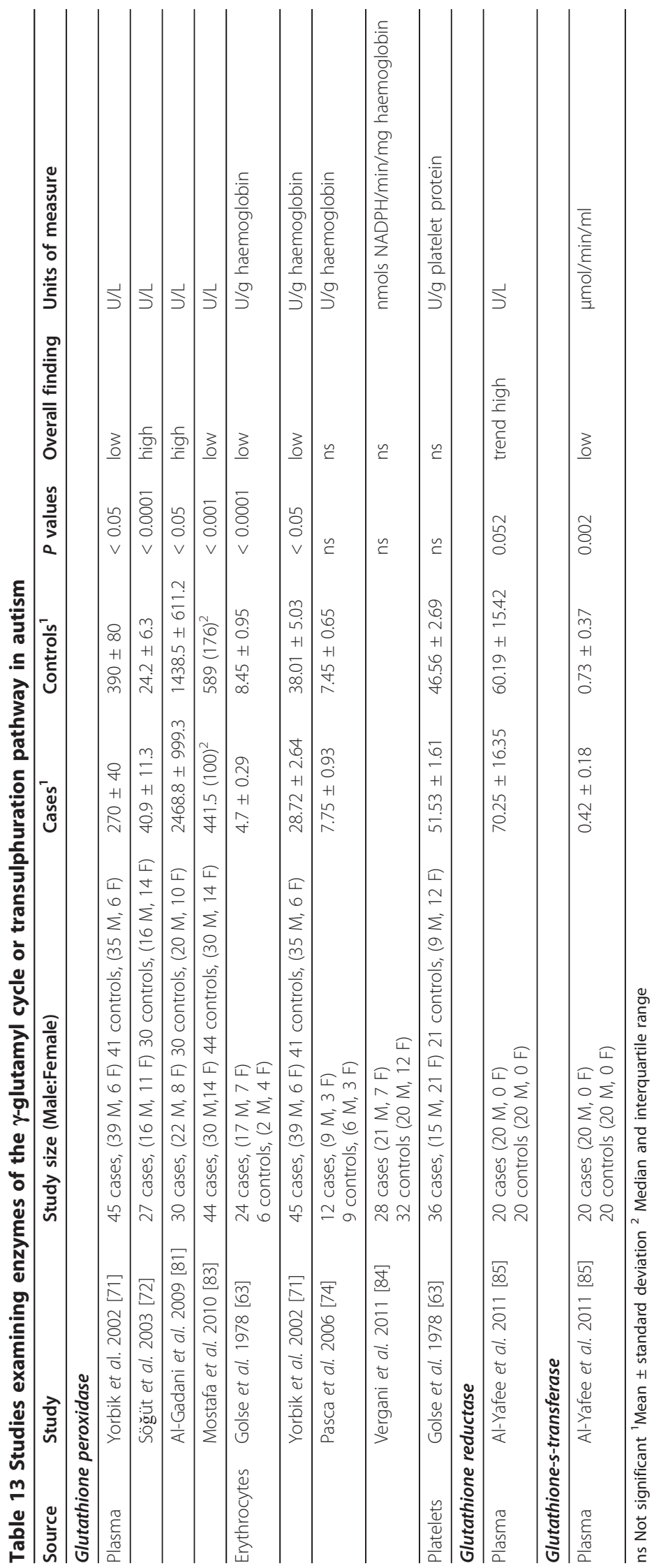


Vitamin B6, in the form of pyridoxal-5'-phosphate, is the cofactor for 5 enzymes in the $\gamma$-glutamyl cycle and trans-sulphuration pathway: cystathionine $\beta$-synthase, cystathione $\gamma$-lyase, cytoplasmic and mitochondrial serine hydroxymethyltransferase and glycine decarboxylase in the mitochondria. The significant increase in plasma vitamin $\mathrm{B} 6$ in many children with autism spectrum disorders $[73,76,87,92,93]$ could potentially reflect diminished cellular uptake or inefficiency of cells to retain or store B6. Impaired bioavailability of vitamin B6 may affect the nervous system because it is required for the synthesis of neurotransmitters including serotonin, dopamine and taurine [110]. There is clearly a need to test whether cellular vitamin B6 is diminished in autism spectrum disorders. In addition, erythrocyte selenium was shown to be significantly lower in one study of children with autistic disorder [78] although there was no significant difference in GPx activity which contains selenium in its active site. These observations coupled with the findings of the intervention studies [46,47] suggest that future studies should examine multiple nutritional status biomarkers of pathways linked with the $\gamma$ glutamyl cycle (e.g. cysteine, folate, vitamin B12, vitamin B6) to determine more effective and accurate risk factor analysis.

The association between the genes of the $\gamma$-glutamyl cycle and autistic disorder is not well studied, although recently a relatively large study using a pathway approach showed a three-SNP joint interaction effect for glutaredoxin, glutaredoxin 3 and cystathione lyase $(\mathrm{OR}=3.78$, $95 \%$ CI: $2.36,6.04$ ) as well as marginal associations for cystathione lyase, the gamma-glutamylcysteine synthetase, catalytic subunit and glutaredoxin 3 suggesting that variation in genes involved in counterbalancing oxidative stress may contribute to autism [94]. The clinical significance of the borderline association between the GST$M^{*} 1$ gene deletion $(G S T-M 1 * 0)$ and autistic disorder $[47,96]$ and the interaction between the GST-M1*0 deletion and the reduced folate carrier 80A > G [47] has yet to be established. GST-M1*0Frequencies range from 42 $60 \%$ in Caucasians [111] and GST-M1*0 appears to be associated with social behavioural changes in mice compared to wild type [112]. No significant associations were found for $G S T-T^{*} 1$ [47]. Although no association between GST-P1 has been shown in children with autism $[94,97]$, the GSTP1*A haplotype was over-transmitted

to mothers of children with autistic disorder (OR 2.67 95\% confidence interval, 1.39- 5.13) [113]. Bowers et al 2011 did not find an association with autistic disorder and other members of the two GST super-families, many of which have GPx activity [22].

The observation that cytostolic and mitochondrial glutathione redox ratios are significantly lower in lymphoblastoid cell lines obtained from children with autistic disorder than their non-autistic siblings [80] coupled with a positive correlation between low natural killer cell activity and reduced glutathione levels in children with autistic disorder [79] suggests that these cells may be more GSH dependent. It is reasonable to hypothesise that children with autistic disorder could benefit from supplementation with glutathione or its precursors. Studies are needed to establish the relationship between extracellular and intracellular glutathione in its oxidised and reduced form because intracellular may ultimately be a better biomarker to study cellular effects proposed in theoretical models.

Finally, phenotypic approaches have been taken to study resistance to environmental or endogenous stressors that are thought to be causative agents for other diseases (e.g. cancer) using lymphocytes or fibroblasts [114-118]. This approach has the advantage that it integrates the effect of both genetic background and nutritional status of the cells in evaluating disease susceptibility. The only published study applying this approach to date in autistic disorder found that the GSH:GSSG was significantly lower in whole cell extracts and mitochondria from lymphoblastoid cells obtained from children with autistic disorder compared to controls but there was no difference in response to nitrosative stress as measured by GSH:GSSG in mitochondria [80].

The consistent observations indicating a role for glutathione metabolism in autism spectrum disorders highlight the potential role of glutathione in them. Replication of these results by other research groups in a wider range of populations is required, however, before definite conclusions can be made. Meta-analyses of observational studies are subject to confounding and selection bias which can distort the findings to produce spurious results [119]. We have been careful not to make our meta-analyses a prominent component of the review, but rather to use the data to identify the extent of confounding and selection biases and to examine possible sources of heterogeneity between the results of individual observational studies.

Common challenges for any systematic review of studies investigating autism spectrum disorders include changes in the criteria for diagnosis and laboratory methodology, the emphasis of early studies on individual metabolites rather than metabolic systems (e.g. one carbon metabolism), and low statistical power. Only a few studies matched cases and controls for age $[60,68,74,75,83]$ and/or gender $[48,60,75,83,89]$ despite the acknowledged difference in prevalence between genders [99], and most did not state the source of controls $[48,59,60,63,68-70$, $73,74,76,78,81,84]$.

Only two of the reviewed studies corrected for multiple comparisons (e.g. Bonferroni or Nyholt correction) 
$[86,97]$. The few studies that matched cases with controls did not use a paired method of analysis such as $\mathrm{McNe}$ mar's test which biases the results towards null. Further, we were unable to replicate the $\mathrm{p}$ values for three studies $[46,47,87]$.

\section{Conclusions}

This review of published studies indicates that evidence for the involvement of the $\gamma$-glutamyl cycle and transsulphuration pathway in autism spectrum disorders should be further explored with higher quality and lower risk bias studies to in order to ascertain the significance of these pathways with respect to clinical outcomes. Trends noted from currently published studies include decreased total glutathione and increased GSSG in children with autism spectrum disorders with no association found between homocysteine or cystathione in these children. There is a trend for cysteine to be lower in children with autistic disorder but not in other autism spectrum disorders. There is a need for large, well designed studies that link metabolites, co-factors and genes of the $\gamma$-glutamyl cycle and trans-sulphuration pathway with objective behavioural outcomes to be conducted in children with autism spectrum disorders. Future risk factor analysis of autism spectrum disorders should include consideration of multiple biomarkers of nutrients involved in pathways linked with the $\gamma$-glutamyl cycle and the interaction of genotype with nutritional status.

\section{Abbreviations \\ ADI-R: Autism diagnostic interview - revised; ALAD: Delta aminolevulinic acid dehydratase; CARS: Childhood Autism Rating Scale; CNS: Central nervous system; d.f.: Degrees freedom; DSM: American Psychiatric Association's Diagnostic and Statistical Manual of Mental Disorders; fGSH: Free reduced glutathione; GCL: Glutamate cysteine ligase; GCT: $\gamma$-glutamyl cyclotransferase; GGT: $\gamma$-glutamyl-transferase; GPx: Glutathione peroxidase; GSH: Reduced glutathione; GSH:GSSG: Glutathione redox ratio; GSH-R: Glutathione reductase; GS: Glutathione synthetase; GSSG: Oxidised glutathione; GST: Glutathione-S-transferases; $\mathrm{Mg}^{2+}$ : Magnesium ions; $\mathrm{Mn}^{2+}$ : Manganese ions; $\mathrm{Q}$ : Cochran's Q (a measure of statistical heterogeneity); SMD: Standardised mean difference; tGSH: Total glutathione}

\section{Acknowledgements}

The authors wish to thank Mr Maxime Francois for his translation of Golse et al. 1978. The comments and suggestions provided by the anonymous reviewers significantly improved this manuscript and we greatly appreciate their efforts.

\section{Author details \\ ${ }^{1}$ Sansom Institute for Health Research, University of South Australia, City East Campus, Adelaide, SA 5000, Australia. ${ }^{2}$ Food and Nutritional Sciences, Commonwealth Scientific and Industrial Research Organisation, Kintore Ave, Adelaide, SA 5000, Australia.}

\section{Authors' contributions}

PM was responsible for all aspects of the manuscript. MA, CO'D and PT checked the references, PM and CO'D assessed the quality of included studies and the draft was reviewed by MA, CO'D, PT and MF. All authors read and approved the final manuscript.

\section{Competing interests}

The authors declare that they have no competing interests.

Received: 25 September 2011 Accepted: 24 April 2012

Published: 24 April 2012

\section{References}

1. Wing L, Gould J: Severe impairments of social interaction and associated abnormalities in children: epidemiology and classification. J Autism Dev Disord 1979, 9:11-29.

2. Baird G, Simonoff E, Pickles A, Chandler S, Loucas T, Meldrum D, Charman T: Prevalence of disorders of the autism spectrum in a population cohort of children in South Thames: the Special Needs and Autism Project (SNAP). Lancet 2006, 368:210-215.

3. Baron-Cohen S, Scott FJ, Allison C, Williams J, Bolton P, Matthews FE, Brayne C: Prevalence of autism-spectrum conditions: UK school-based population study. Br J Psychiatry 2009, 194:500-509.

4. Wazana A, Bresnahan M, Kline J: The autism epidemic: fact or artifact? J Am Acad Child Adolesc Psychiatry 2007, 46:721-730.

5. Folstein SE, Rosen-Sheidley B: Genetics of autism: complex aetiology for a heterogeneous disorder. Nat Rev Genet 2001, 2:943-955.

6. Ritvo ER, Freeman BJ, Pingree C, Mason-Brothers A, Jorde $L$, Jenson WR, McMahon WM, Petersen PB, Mo A, Ritvo A: The UCLA-University of Utah epidemiologic survey of autism: prevalence. Am J Psychiatry 1989, 146:1032-1036.

7. Geschwind DH: Autism: many gnes, common pathways. Cell 2009, 135:391-395.

8. Autism Genome Project Consortium: Functional impact of global rare copy number variation in autism spectrum disorders. Nature 2010, 466:368-372

9. der Veenstra-van Weele J, Cook EH Jr: Molecular genetics of autism spectrum disorder. Mol Psychiatry 2004, 9:819-832.

10. Grandjean P, Landrigan PJ: Developmental neurotoxicity of industrial chemicals. Lancet 2006, 368:2167-2177.

11. Kern J, Jones AM: Evidence of toxicity, oxidative stress and neuronal insult in autism. Journal of Toxicology and Environmental Health, Part B 2006, 9:485-499.

12. Slotkin TA, Vevin ED, Seidler FJ: Comparative developmental neurotoxicity of organophsphate insecticides: effects on brain development are separable from systemic toxicity. Environ Health Perspect 2006, 114:746-751.

13. van den Pol AN: Viral infections in the developing and mature brain. Trends Neurosci 2006, 29:398-406.

14. Horvath K, Perman J: Autistic disorder and gastrointestinal disease. Current Opinions in Pediatrics 2002, 14:583-587.

15. White JF: Intestinal pathophysiology in autism. Experimental Biological Medicine 2003, 228:639-649.

16. Chauhan A, Chauhan V: Oxidative stress in autism. Pathophysiology 2006, 13:171-181.

17. Newschaffer CJ, Croen LA, Daniels J, Giarelli E, Grether JK, Levy SE, Mandell DS, Miller LA, Pinto-Martin J, Reaven J, et al: The epidemiology of Autism spectrum disorders. Annu Rev Public Health 2007, 28:235-258.

18. Wang L, Angley MT, Gerber JP, Young RL, Abarno DV, McKinnon RA, Sorich MJ: Is urinary indolyl-3 acryloylglycine a biomarkers for autism with gastrointestinal symptoms? Biomarkers 2009, 14:596-609.

19. Yap IKS, Angley M, Veselkov KA, Holmes E, Lindon JC, Nicholson JK: Urinary metabolic phenotyping differentiates children with autism, from their unaffected siblings and age-matched controls. J Proteome Res 2010, 9:2996-3004.

20. Hertz-Picciotto I, Croen LA, Hansen R, Jones CR, van Water J, Pessah IN: The CHARGE study: an epidemiologic investigation of genetic and environmental factors contributing to autism. Environ Health Perspect 2006, 114:1119-1125.

21. Meister A: Glutathione. In The Liver: Biology and Pathobiology. Volume 2. Edited by: Aria IM, Jakoby WB, Popper H, Schachter D, Shafritz DA. New York: Raven Press; 1988:401-417.

22. Hayes JD, Strange RC: Glutathione S-transferase polymorphisms and their biological consequences. Pharmacology 2000, 61:154-166.

23. Lu SC: Regulation of hepatic glutathione synthesis: current concept and controversies. FASEB 1999, 13:1169-1183. 
24. Chance $B$, Sies $H$, Boveris A: Hydroperoxide metabolism in mammalian organs. Physiol Rev 1979, 59:527-605.

25. Jackson AL, Loeb LA: The contribution of endogenous sources of DNA damage to the multiple mutations in cancer. Mutat Res 2001, 477:7-21.

26. Shen Z, Wu W, Hazen SL: Activated leukocytes oxidatively damage DNA RNA, and the nucleotide pool through halide-dependent formation of hydroxyl radical. Biochemistry (Mosc) 2000, 39:5474-5482.

27. Fidelus RK, Tsan MF: Glutathione and lymphocyte activation: a function of aging and auto-immune disease. Immunology 1987, 61:503-508.

28. Filomeni G, Rotilio G, Ciriolo MR: Cell signalling and the glutathione redox system. Biochem Pharmacol 2002, 64:1057-1064.

29. Hwang C, Sinsky AJ, Lodish HF: Oxidised redox state of glutathione in the endoplasmic reticulum. Science 1992, 257:1496-1502.

30. Sies H: Glutathione and its cellular functions. Free Radic Biol Med 1999, 27:916-921.

31. Dalton TP, Chen Y, Schneider SN, Nebert DW, Shertzer HG: Genetically altered mice to evaluate glutathione homeostasis in health and disease. Free Radic Biol Med 2004, 37:1511-1526.

32. Dickinson DA, Levonen AL, Moellering DR, Arnold EK, Zhang H, DarleyUsmar VM, Forman HJ: Human glutamate cysteine ligase gene regulation through the electrophile response element. Free Radic Biol Med 2004, 37:1152-1157.

33. Meister A, Tate SS: Glutathione and related gamma-glutamyl compounds: biosynthesis and utilization. Annu Rev Biochem 1976, 45:559-604.

34. Meister A, Anderson ME: Glutathione. Annual Reviews of Biochemistry 1983 45:711-760.

35. Rotruck JT, Pope AL, Ganther HE, Swanson AB, Hafeman DG, Hoekstra WG Selenium: biochemical role as a compontentof glutathione peroxidase. Science 1972, 179:588-590.

36. Boyland $\mathrm{E}$, Chasseaud LF: The role of glutathione and glutathione Stransferases in mercapturic acid biosynthesis. Adv Enzymol Relat Areas Mol Biol 1969, 32:173-219.

37. Ikeda $Y$, Taniguchi N: Gene expression of gamma-glutamyltranspeptidase. Methods Enzymol 2005, 401:408-425.

38. Hanigan HM, Pitot HC: Carcinogenesis 1985, 6:165.

39. Finkelstein JD: Methionine metabolism in mammals. J Nutr Biochem 1990, $1: 228-237$

40. Vitvitsky V, Thomas M, Ghorpade A, Gendelman HE, Banerjee R: A functional transsulfuration pathway in the brain links to glutathione homeostasis. J Biol Chem 2006, 281:35785-35793.

41. Jones DP: Redefining oxidative stress. Antioxidant and Redox Signalling 2006, 8:1865-1879.

42. Kemp M, Go YM, Jones DP: Non-equilibrium thermodynamics of thiol/ disulfide redox systems: a perspective on redox systems biology. Free Radic Biol Med 2008, 44:921-937.

43. Schafer FQ, Beuttner GR: Redox environment of the cell as viewed through the redox state of the glutathione disulfide/glutathione couple. Free Radic Biol Med 2001, 30:1191-1212.

44. Kulkarni A, Wilson DM: The involvement of DNA-damage and repair defects in neurological dysfunction. Am J Hum Genet 2008, 82:539-566.

45. Sen CK: Cellular thiols and redox-regulated signal transduction. Current Topics in Cell Regulation 2000, 36:1-30

46. James SJ, Cutler P, Melnyk S, Jernigan S, Janak L, Gaylor DW, Neubrander JA: Metabolic biomarkers of increased oxidative stress and impaired methylation capacity in children with autism. Am J Clin Nutr 2004, 80:1611-1617.

47. James SJ, Melnyk S, Jernigan S, Cleves MA, Halsted CH, Wong DH, Cutler P, Bock K, Boris M, Bradstreet JJ, et al: Metabolic endophenotype and related genotypes are associated with oxidative stress in children with autism. Am J Med Genet B 2006, 141:947-956.

48. James SJ, Melnyk S, Fuchs G, Reid T, Jernigan S, Pavliv O, Hubanks A, Gaylor DW: Efficacy of methylcobalamin and folinic acid treatment on glutathione redox status in children with autism. Am J Clin Nutr 2009, 89:425-430.

49. Rossignol DA, Rossignol LW, James SJ, Melnyk S, Mumper E: The effects of hyperbaric oxygen therapy on oxidative stress, inflammation, and symptoms in children with autism: an open-label pilot study. BMC Pediatrics 2007, 7:36, doi:10.1186/1471-2431-7-36.

50. Rose S, Melnyk S, Savenka A, Hubanks A, Jernigan S, Cleves M, James SJ: The frequency of polymorphisms affecting lead and mercury toxicity among children with autism. Am J Biochem Biotech 2008, 4:85-94.
51. American Psychiatric Association: Diagnostic and Statistical Manual of Mental Disorders: text revision (DSM-IV-R). 4 edition. Washington D.C.; American Psychiatric Association; 2000.

52. Schopler E, Reichler R, Renner B: Toward objective classification of childhood autism: Childhood Autism Rating Scale (CARS). J Autism Dev Disord 1980, 10:91-103

53. Wells GA, Shea B, O'Connell D, Peterson J, Welch V, Losos M, Tugwell P: The Newcastle-Ottawa Scale (NOS) for assessing the quality of nonrandomised studies in meta-analyses. Book The Newcastle-Ottawa Scale (NOS) for assessing the quality of nonrandomised studies in metaanalyses (Editor ed.^eds.) City: Ottawa: Ottawa Health Research Institute.

54. Moretti P, Sahoo T, Hyland K, Bottiglieri R, Peters SU, Del Gaudio D, Roa B, Curry S, Zhu H, Finnell RH, et al: Cerebral folate deficiency with developmental delay, autism and response to folinic acid. Neurology 2005, 64:1088-1090.

55. Higgins JPT, Altman DG, Sterne JAC: Chapter 8: Assessing risk of bias in included studies Version 5.1.0 (updated March 2011). The Cochrane Collaboration 2011 [http://www.cochrane-handbook.org], edn. Melbourne; 2011.

56. Australian National Health and Medical Research Council: A guide to the development, implementation and evaluation of clinical practice guidelines Canberra, Australia: Australian Government Publishing Service; 1999.

57. Cohen J: A coefficient of agreement for nominal scales. Educ Psychol Meas 1960, 20:37-46.

58. The Cochrane Collaboration: Review Manager (RevMan) [Computer program] Copenhagen: The Nordic Cochrane Centre; 2011.

59. Adams M, Lucock M, Stuart J, Fardell S, Baker K, Ng X: Preliminary evidence for involvement of the folate gene polymorphism $19 \mathrm{bp}$ deletion-DHFR in occurrence of autism. Neurosci Lett 2007, 422:24-29.

60. Pasca S, Dronca E, Kaucsar T, Craciun EC, Endreffy E, Ferencz BK, Iftene F, Benga I, Cornean R, Banerjee R, Dronca M: One carbon metabolism disturbances and the C677T MTHFR gene polymprhism in children with autism stpectrum disorders. J Cell Mol Med 2009, 13:4229-4238.

61. Stroup DF, Berlin JA, Morton SC, Olkin I, Williamson GD, Rennie D, Moher D, Becker BJ, Sipe TA, Thacker SB: Meta-analysis of observational studies in epidemiology: a proposal for reporting. J Am Med Assoc 2000, 283:2008-2012.

62. Little J, Higgins JPT, loannidis JPA, Moher D, Gagnon F, von Elm E, Khoury MJ, Cohen B, Davey-Smith G, Grimshaw J, et al: Strengthening the reporting of genetic association studies (STREGA)-an extension of the strengthening the reporting of observational studies in epidemiology (STROBE) statement. J Clin Epidemiol 2009, 62:597-608.

63. Golse B, D-R P, Durosay P, Puget K, Michelson AM: Perturbation de deux enzymes: la superoxyde-dismutase 1 et la glutathion-peroxydase dans la psychose infantile de developpement (autisme infantile). (Alterations in two enzymes: superoxide dismutase and glutathione peroxidase in infantile autism). Revue Neurologique (Paris) 1978, 134:699-705.

64. Bertoglio K, James SJ, Deprey L, Brule N, Hendren R: Pilot study of the effect of methyl B12 treatment on behavioural and biomarker measures in children with autism. J Altern Complement Med 2010, 16:555-560.

65. Adams JB, Baral M, Geis E, Mitchell J, Ingram JL, Hensley A, Zappia I, Newmark S, Gehn E, Rubin RA, et al: Safety and efficacy of oral DMSA therapy for children with autism spectrum disorders: part A - medical results. BMC Clin Pharmacol 2009, 9:1-22.

66. Geier DA, Geier MR: A clinical and laboratory evaluation of methionine cycle-transsulfuration and androgen pathway markers in children with autistic disorders. Horm Res 2006, 66:182-188.

67. Adams JB, Baral M, Geis E, Mitchell J, Ingram J, Hensley A, Zappia I, Newmark S, Gehn E, Rubin RA, et al: The severity of autism is associated with toxic metal body burden and red blood cell glutathione levels. J Toxicol 2009, 532640, 7 pages, 2009. doi:10.1155/2009/532640.

68. Rolf LH, Haarmann FY, Grotemeyer K-H, Kehrer H: Serotonin and amino acid content in platelets of autistic children. ACTA Psychiatrica Scandinavia 1993, 87:312-316.

69. Visconti P, Piazzi S, Posar A, Santi A, Pipitone E, Rossi PG: Amino acids and infantile autism. Developmental Brain Dysfunction 1994, 7:86-92.

70. D'Eufemia P, Finochhiaro R, Celli M, Viozzi L, Monteleone D, Fiardini O: Low serum tryptophan to large neutral amino acids ratio in idiopathic infantile autism. Biomed Pharmacother 1995, 49:288-292.

71. Yorbik O, Sayal A, Akay C, Akbiyik DI, Sohmen T: Investigation of antioxidant enzymes in children with autistic disorder. Prostaglandins Leukot Essent Fatty Acids 2002, 67:341-343. 
72. Sogut S, Zoroglu SS, Ozyurt H, Yilmaz HR, Ozugurlu F, Sivash E, Yetkin O, Yanik $M$, Tutkun $H$, Savas HA, et al: Changes in nitric oxide levels and antioxidant enzyme activities may have a role in the pathophysiological mechanisms involved in autism. Clin Chim Acta 2003, 331:111-117.

73. Adams JB, Holloway C: Pilot study of a moderate dose multivitamin/ mineral supplement for children with autistic spectrum disorder. J Altern Complement Med 2004, 10:1033-1039.

74. Pasca S, Nemes B, Vlase L, Gagyi C, Dronca E, Miu A, Dronca M: High levels of homocysteine and low serum paraoxonase 1 arylesterase activity in children with autism. Life Sci 2006, 78:2244-2248.

75. Shinohe A, Hashimoto K, Nakamura K, Tsujii M, Iwata Y, STsuchiya KJ, Sekine Y, Suda S, Suzuki K, Sugihara G-l, et al: Increased serum levels of glutamate in adult patients with autism. Prog Neuropsychopharmacol Biol Psychiatry 2006, 30:1472-1477.

76. Adams JB, George F, Audhya T: Abnormally high plasma levels of vitamin B6 in children with autism not taking supplements compared to controls not taking supplements. J Altern Complement Med 2006, 12:59-63.

77. Suh JR, Walsh WJ, McGinnis WR, Lewis A, Ames BN: Altered sulfur amino acid metabolism in immune cells of children diagnosed with autism. Am J Biochem Biotech 2008, 4:105-113.

78. Jory J, McGinnis WR: Red-cell trace minerals in children with autism. Am J Biochem Biotech 2007, 4:101-104.

79. Vojdani A, Mumper E, Granpeesheh D, Mielke L, Traver D, Bock K, Hirani K, Neubrander JA, Woeller KN, O'Hara N, et al: Low natural killer cell cytotoxic activity in autism: the role of glutathione IL-2 and IL-15. J Neuroimmunol 2008, 205:148-154.

80. James SJ, Rose S, Melnyk S, Jernigan S, Blossom S, Pavliv O, Gaylor DW: Cellular and mitochondrial glutathione redox imbalance in lymphoblastoid cells derived from children with autism. FASEB 2009, 23:2374-2383.

81. Al-Gadani Y, El-Ansary A, Attas O, Al-Ayadhi L: Metabolic biomarkers related to oxidative stress and antioxidant status in Saudi autistic children. Clin Biochem 2009, 42:1032-1040.

82. Pastural E, Ritchie S, Lu Y, Jin W, Kavianpour A, Su-Myat K, Heath D, Wood PL, Fisk M, Goodenowe DB: Novel plasma phospholipid biomarkers of autism: mitochondrial dysfunction as a putative causative mechanism. Prostaglandins Leukot Essent Fatty Acids 2009, 81:253-264.

83. Mostafa GA, El-Hadidi ES, Hewedi DH, Abdou MM: Oxidative stress in Egyptian children with autism: relation to autoimmunity. J Neuroimmunol 2010, 219:114-118

84. Vergani L, Lanza C, Rivaro P, Abelmoschi ML, Genti S, Veneselli E, Minniti G, Grasselli E, Canesi L, Voci A: Metals, metallothioneins and oxidative stress in blood of autistic children. Res Autism Spect Disord 2011, 5:286-293.

85. Al-Yafee YA, LY A-A, Haq SH, El-Ansary AK: Novel metabolic biomarkers related to sulfur dependent detoxification pathways in autistic patients of Saudi Arabia. BMC Neurol 2011, 11:139, doi:10.1186/1471-2377-11-139.

86. Tirouvanziam R, Obukhanych TV, Laval J, Aronov PA, Libove R, Banerjee AG, Parker KJ, O'Hara R, Herzenberg LA, Herzenberg LA, Hardan AY: Distinct plasma profile of polar neutral amino acids, leucine and glutamate in children with autism spectrum disorders. J Autism Dev Disord 2011, 42(5):827-836.

87. Adams JB, Audhya T, McDonough-Means S, Rubin RA, Quig D, Geis E, Gehn E, Loresto M, Mitchell J, Atwood S, et al: Nutritional and metabolic status of children with autism vs. neurotypical children, and the association with autism severity. Nutr Metab 2011, 8:34.

88. Aldred S, Moore KM, Fitzgerald M, Waring RH: Plasma amino acid levels in children with autism. J Autism Dev Disord 2003, 33:93-97.

89. Arnold GL, Hyman SL, Mooney RA, Kirby RS: Plasma amino acids profiles in children with autism: potential risk of nutritional deficiencies. J Autism Dev Disord 2003, 33:449-454.

90. Geier DA, Kern JK, Garver CR, Adams JB, Audhya T, Nataf R, Geier MR: Biomarkers of environmental toxicity and susceptibility in autism. $J$ Neurol Sci 2009, 280:101-108.

91. Geier DA, Kern J, Garver CR, Adams JB, Audhya T, Geier MR: A prospective study of transsulfuration biomarkers in autistic disorders. Neurochemistry Research 2009, 34:386-393.

92. Siva Sankar DV: Plasma levels of folates, riboflavin, vitamin B6 and ascorbate in severely disturbed children. J Autism Dev Disord 1979, 9:73-82.

93. Khaleeluddin K, Philpott WH: I. The clinical report of ecologic and nutritional disorders in chronic mental and physical degenerative diseases. II. The significance of $\mathrm{B} 6$ and methionine metabolic disorders in mental disease. J Appl Nutr 1980, 32:37-52.

94. Bowers K, Li Q, Bressler J, Avramopoulos D, Newschaffer C, Fallin MD: Glutathione pathway gene variation and risk of autism spectrum disorders. J Neurodevelop Disord 2011, 3:132-143.

95. Ming X, Johnson WG, Stenroos S, Mars A, Lambert GH, Buyske S: Genetic variant of glutathione peroxidase 1 in autism. Brain Dev 2010, 32:105-109.

96. Buyske S, Williams TA, Mars AE, Stenroos ES, Ming SX, Wang R, Sreenath M, Factura MF, Reddy C, Lambert GH, Johnson WG: Analysis of case-parent trios at a locus with a deletion allele association of GSTM1 with autism. BMC Genetics 2006, 7:8, doi:10.1186/1471-2156-7-8.

97. Serajee FJ, Nabi R, Zhong H, Huq AHMM: Polymorphisms in xenobiotic metabolism genes and autism. J Child Neurol 2004, 19:413-417.

98. Lowe TL, Cohen DJ, Miller S, Young JG: Folic acid and $\mathrm{B}_{12}$ in autism and neuropsychiatric disturbances of childhood. J Am Acad Child AdolesC Psychiatry 1981, 20:104-111.

99. Fombonne E: Epidemiological surveys of autism and other pervasive developmental disorders: an update. J Autism Dev Disord 2003, 33:365-382.

100. Woods JS, Echeverria D, Heyer NJ, Simmonds PL, Wilkerson J, Farin FM: The association between genetic polymorphisms of coproporphyringogen oxidase and an atypical porphyrinogenic response to mercury exposure in humans. Toxicol Appl Pharmacol 2005, 206:113-120.

101. Montenegro MF, Barbosa F Jr, Sandrim VC, Gerlach RF, Tanus-Santos JE: A polymprphism in the delta-aminolevulinic acid dehydratase gene modifies plasma/whole blood lead ratio. Arch Toxicol 2006, 80:394-398.

102. Astrin KH, Bishop DF, Wetmur JG, Kaul B, Davidow B, Desnick RJ: Deltaaminolevulinic acid dehydratase isozymes and led toxicity. Ann NY Acad Sci 1987, 514:23-29.

103. Lord C, Rutter M, Le Couteur A: Autism diagnostic interview - revised: a revised version of a diagnostic interview for caregivers of individuals with possible pervasive developmental disorders. J Autism Dev Disord 1994, 24:659-686.

104. Berk M, Plein H, Ferreira D: Platelet glutamate receptor supersensitivity in major depressive disorder. Clin Neuropharmacol 2003, 24:129-132.

105. Berk M, Plein H, Belsham B: The specificity of platelet glutamate receptor super-sensitivity in psychotic disorders. Life Sci 2000, 66:2427-2432.

106. Berk M, Plein H, Czismadia T: Supersensitive platelet glutamate receptors as a possible peripheral marker in schizophrenia. Int Clin Psychopharmacol 1999, 14:119-122.

107. Shinohe A, Mori M: Reply to: The hyperglutamatergic hypothesis of autism. Prog Neuropsychopharmacol Biol Psychiatry 2008, 32:912-913.

108. Langosch D, Becker CM, Betz H: The inhibitory glycine receptor: a ligandgated channel of the central nervous system. Eur J Biochem 1990, 194:1-8.

109. Zafra F, Aragon C, Olivares L, Danbolt NC, Grimenez C, Storm-Mathisen J: Glycine transporters are differentially expressed among CNS cells. J Neurosci 1995, 75:3952-3969.

110. Gerster H: The importance of vitamin-B6 for development of the infant: human medical and animal experimentation studies. Z Ernährungswiss 1996, 35:309-317.

111. Garte S, Gaspari L, Alexandrie AK, Ambrosone C, Autrup H, Autrup JL, Baranova H, Bathum L, Benhamou S, Boffetta P, et al: Metabolic gene polymorphism frequencies in control populations. Cancer Epidemiol Biomarkers Prev 2001, 10:1239-1248.

112. Yochum $\mathrm{CL}$, Bhattacharya P, Patti L, Mirochnitchenko O, Wagner GC: Animal model of autism using GST-M1 knockout mice and early postnatal sodium valproate treatment. Behav Brain Res 2010, 210:202-210.

113. Williams TA, Mars AE, Buyske SG, Stenroos ES, Wang R, Factura-Santiago MF, Lambert GH, Johnson WG: Risk of autistic disorder in affected offspring of mothers with a glutathione S-transferase P1 haplotype. Arch Pediatr Adolesc Med 2007, 161:356-361.

114. Rothfuss A, Schuetz P, Bochum S, Volm T, Eberhardt E, Kreienberg R, Vogel W, Speir G: Induced micronucleus frequencies in peripheral lymphocytes as a screening test for carriers of a BRCA1 mutation in breast cancer families. Cancer Res 2000, 60:390-394.

115. El-Zein RA, Schabath MB, Etzel CJ, Lopez MS, Franklin JD, Spitz MR: Cytokinesis-blocked micronucleus assay as a novel biomarker for lung cancer risk. Cancer Res 2006, 66:6449-6456.

116. Varga D, Hoegel J, Maier C, Jainta S, Hoehne M, Patino-Garcia B, Michel I, Schwarz-Boeger $U$, Kiechle M, Kreienberg $R$, Vogel W: On the difference of 
micronucleus frequencies in peripheral blood lymphocytes between breast cancer patients and controls. Mutagenesis 2006, 21:313-320.

117. Willems P, Claes K, Baeyens A, Vandersickel V, Werbrouck J, de Ruyck K, Poppe B, van den Broecke R, Makar A, Marras E, et al: Polymorphisms in non-homologous end-joining genes associated with breast cancer risk and chromosomal radiosensitivity. Genes Chromosomes Cancer 2008, 47:137-148.

118. El-Zein RA, Fenech M, Lopez MS, Spitz MR, Etzel CJ: Cytokinesis-blocked micronucleus cytome assay biomarkers identify lung cancer cases amongst smokers. Cancer Epidemiol Biomarkers Prev 2008, 17:1111-1119.

119. Egger M, Schneider M, Davey Smith G: Spurious precision? Meta-analysis of observational studies. Br Med J 1998, 316:140-144.

doi:10.1186/1743-7075-9-35

Cite this article as: Main et al:: The potential role of the antioxidant and detoxification properties of glutathione in autism spectrum disorders: a systematic review and meta-analysis. Nutrition \& Metabolism 2012 9:35.

\section{Submit your next manuscript to BioMed Central} and take full advantage of:

- Convenient online submission

- Thorough peer review

- No space constraints or color figure charges

- Immediate publication on acceptance

- Inclusion in PubMed, CAS, Scopus and Google Scholar

- Research which is freely available for redistribution

Submit your manuscript at www.biomedcentral.com/submit
C Biomed Central 